NBER WORKING PAPER SERIES

\title{
OCCUPATIONAL SKILL PREMIA AROUND THE WORLD: NEW DATA, PATTERNS AND DRIVERS
}

\author{
David Kunst \\ Richard B. Freeman \\ Remco Oostendorp \\ Working Paper 26863 \\ http://www.nber.org/papers/w26863 \\ NATIONAL BUREAU OF ECONOMIC RESEARCH \\ 1050 Massachusetts Avenue \\ Cambridge, MA 02138 \\ March 2020, Revised March 2021
}

Previously circulated as "Occupational Skill Premia around the World." We thank Kathleen G. Beegle, Claudio E. Montenegro, David Newhouse and Aditi Mishra for their help in accessing the World Bank I2D2 surveys. The views expressed herein are those of the authors and do not necessarily reflect the views of the National Bureau of Economic Research.

NBER working papers are circulated for discussion and comment purposes. They have not been peer-reviewed or been subject to the review by the NBER Board of Directors that accompanies official NBER publications.

(C) 2020 by David Kunst, Richard B. Freeman, and Remco Oostendorp. All rights reserved. Short sections of text, not to exceed two paragraphs, may be quoted without explicit permission provided that full credit, including $\odot$ notice, is given to the source. 
Occupational Skill Premia around the World: New Data, Patterns and Drivers

David Kunst, Richard B. Freeman, and Remco Oostendorp

NBER Working Paper No. 26863

March 2020, Revised March 2021

JEL No. F1,I2,J2,J3,J5,O3

\begin{abstract}
$\underline{\text { ABSTRACT }}$
Firms hire workers to undertake tasks and activities associated with particular occupations, which makes occupations a fundamental unit in economic analyses of the labor market. Using a unique dataset on pay in identically defined occupations in developing and advanced countries, we find that in most countries occupational skill premia narrowed substantially from the 1950s to the 1980s, then widened through the 2000s, creating a U-shaped pattern of change. The narrowing was due in part to the huge worldwide increase in the supply of educated workers. The subsequent widening was due in part to the weakening of trade unions and a shift in demand to more skilled workers associated with rising trade. The data indicate that supply, demand, and institutional forces are all drivers of occupational skill premia, ruling out simple single factor explanations of change. The paper concludes with a call for improving the collection of occupational wage data to understand future changes in the world of work.
\end{abstract}

David Kunst

Vrije Universiteit Amsterdam

De Boelelaan 1105

1081 HV Amsterdam

The Netherlands

and Tinbergen Institute

david.m.kunst@gmail.com

Richard B. Freeman

NBER

1050 Massachusetts Avenue

Cambridge, MA 02138

freeman@nber.org
Remco Oostendorp

Vrije Universiteit Amsterdam

De Boelelaan 1105

1081 HV Amsterdam

The Netherlands

and Tinbergen Institute

r.oostendorp@vu.nl

The Occupational Wages around the World 1953-2008 Database is available at https://data.nber.org/oww/ 


\section{Introduction}

Occupations, defined by what people do at work and the knowledge required to do those work tasks, are a fundamental unit in labor market analysis. They are a major determinant of wages, accounting for a greater share of the variance of log wages or earnings than education, arguably because occupations better signal what workers do at a job than does education. ${ }^{1}$

Analytic attention to occupations has, however, varied over time. Human capital analysis directed attention at education and rates of return to years of schooling, superseding an earlier literature on occupational wages and employment (Reder, 1955; Perlman, 1958), Perlman (1958) . Beginning in the 2000s, there has been renewed investigation of occupations as units of analysis. One reasons is concern for how technological change affects the demand for specific tasks, which are occupation associated (Autor et al., 2003). Another is that the explanatory power of occupations for wages relative to that of education also appears to have been rising in recent decades. ${ }^{2}$ In developing countries, where formal educational attainments are relatively low and on-the-job learning is an important component of skill formation, education has never sufficed as an indicator of labor skills.

Nevertheless, analyses of occupational wage differentials worldwide are rare - a gap that Ashenfelter (2012) attributes to the paucity of internationally comparable data on occupational pay. This paper fills this gap by introducing and analyzing an extended version of the "Occupational Wages around the World" (OWW) database Freeman and Oostendorp (2001) that reports wages in many detailed occupations in 192 countries based on the International Labor Organization's "October Inquiry" of pay. From 1953 to 2008, the October Inquiry gathered wages from national statistical offices in more countries and on a greater number of identically defined detailed occupations than any other data source, and then was

\footnotetext{
1 Autor and Handel (2013) find that occupation dummies give an R-squared of 0.61 in accounting for variation of wages in the USA (column 3 of Table 5), compared to 0.39 for education and demography variables (column 1), and that both sets of variables together give an R-square of 0.65 . See also Bessen (2015) for the importance of informal learning on the job for wages and Section 2 for additional crosscountry evidence on the importance of occupations for wage determination.

${ }^{2}$ See Acemoglu and Autor (2011) for the case of the USA and Section 2 where we note that the finding of a growing importance of occupations in wage determination generalizes to a broader cross-country sample.
} 
abandoned. $3^{3}$

We study the determinants of occupational pay differentials in the OWW, considering changes in supply, demand, and labor market institutions. Since World War II, the supply of educated persons has increased greatly due to the phenomenal global increase in formal education, with average years of schooling across countries increasing from about 3 years in 1950 to more than 8 years in 2010 (Barro and Lee, 2013). ${ }^{4}$ Supply is therefore a key variable for the study of skill premia. We identify occupational labor supply effects by combining country level data on the distribution of workers by education across occupations from the World Bank I2D2 database by Montenegro and Hirn (2009) with country-level data on educational attainments from the Barro-Lee database. Keeping the occupational distributions by education fixed over the study period but allowing the educational distribution to change over time gives us an estimate of the effect of the expansion of education on the supply of workers by occupation in a country. To the extent that aggregate changes in educational attainments are exogenous with respect to occupational wages, we can use these estimated occupational supply shifts to identify the effect of changes in occupational labor supply on occupational wages.5

In contrast, our measures of demand and institutions are based on country level data, due to the absence of data on demand for occupations or institutions impacting occupations on a worldwide country basis. For demand, we use GDP per worker and merchandise exports plus imports over GDP as measures of the level and trade orientation of aggregate demand. For union measures, we use country level union density to reflect the effect of institutions on wages. Since we lack measures of demand and unionization at the country-occupation level, we employ a different strategy to assess the impact of these country level variables on skill premia. Our strategy is to estimate separate equations for occupations with differing

\footnotetext{
${ }^{3}$ See Freeman and Oostendorp $(2020)$ for a detailed description of this updated dataset. The data are available for download at https://data.nber.org/oww/.

${ }^{4}$ The expansion of formal education has been accompanied also by large improvements in available outcome measures such as literacy, increasing from $56 \%$ of the world population in 1950 to $86 \%$ in 2016 (Roser and Ortiz-Ospina, 2016).

${ }^{5}$ See Section 3 for a discussion of the exogeneity of our occupational supply measure.
} 
skill levels. All of our regression analyses include country-occupation and period dummy variables so that estimates rely on within country-occupation changes over time.

Section 2 introduces the updated 2020 OWW database together with evidence on the importance of occupations for wages, especially relative to formal education, in a broad sample of countries drawn from the Luxembourg Income Study Database. The Section documents surprisingly similar patterns of change in occupational differentials among countries at different levels of economic development in the OWW data. Differentials narrowed substantially in most countries from the 1950s to 1980s and then widened through the mid 2000s. Section 3 uses country data on the distribution of workers by educational attainment among occupations to estimate how increased levels of education altered the supply of workers to occupations. Our results show that in countries where educational attainments are low, not everyone who works in a skilled occupations also has a high level of formal education. This points to the importance of informal learning on the job, which is taken into account by occupational skill premia.

Section 4 presents our regressions of log wages by country-occupation on supply, demand and union drivers of wages. The estimates indicate that shifts in labor supply narrowed wage differentials between high and low skill occupations. By contrast, increases in trade orientation were associated with increasing wage differentials, driven in particular by developing countries. Also the fall in union density in most countries from the 1980s through the 2000s contributed to the increase of wage differentials by lowering pay primarily for less skilled workers. Section 5 shows that our estimates of the effect of demand, supply, and unionism on occupational pay explain part but not all of the pattern of skill differentials. Section 6 concludes with a review of wage data on occupational differentials from the period after the OWW terminated through the mid-2010s and makes a case for new detailed occupation data to aid analysis of the impact of new technologies on labor demand. The appendices detail the sources of the data and probe the robustness of results. 


\section{Measuring A Half Century of Skill Premia, 1950s-2000s}

To analyze the evolution of occupational skill premia around the world, we use the updated 2020 OWW database, originally developed from the ILO's "October Inquiry" by Freeman and Oostendorp (2000). Beginning in 1953, the Inquiry asked the statistical offices of member states to report wages in 48 narrow (essentially 4-digit ISCO) occupations.6 In 1983, it asked the offices to report on 161 occupations in all major industries.7 $]^{7}$ Forty-five occupations appear in both periods, although since 1983 two of them are reported at a more disaggregated industry level.8 Because the 45 occupations include only two of the universitylevel professional occupations that became more important in the 1980s-2000s, most of our analysis focuses on the full sample of 162 occupations..$^{9}$

Occupational wage data are a potentially valuable complement or alternative to the analysis of educational differentials for three reasons:: (i) surveys often include a larger number of occupational than educational categories, (ii) occupational wages can capture changes in returns to tasks which are possibly non-monotonic in educational levels (e.g. due to labor market polarization and offshoring), and (iii) occupational wages can capture returns to informal learning and skill differences independent of formal educational attainments, which is especially important for developing countries and long-run studies of skill premia.

All of these factors suggest that occupations have as much or more explanatory power in accounting for wage differences than education. Using internationally comparable crosscountry microdata on wages for 47 countries from the Luxembourg Income Study Database

\footnotetext{
${ }^{6}$ For a smaller number of occupations, the data collection of the "October Inquiry" had already started in 1924.

${ }^{7}$ The ILO collects information on 159 occupations but occupation 139 ('government executive official') has subsequently been split in three administrative levels (central, regional/provincial, local) (see Appendix $\mathrm{C}$ in Freeman and Oostendorp, 2020).

${ }^{8}$ The occupations "Mixing- and blending-machine operator" and "Labourer" are reported for the entire chemical industry between 1953-1982, and for "industrial chemicals" and "other chemical products" since 1983.

${ }^{9}$ Of which 3 are only available between 1953 and 1982, and 114 are only available between 1983 and 2008. We note that the full OWW dataset described in Freeman and Oostendorp $(2020)$ includes $164(=3+45+114)$ occupations. This is because for the analyses in this paper, we have collapsed the wage reports for the two occupations in the chemical industry that were reported at a more disaggregated industry level only since 1983, to make their reporting more consistent over the full 1953-2008 reporting period.
} 
(LIS), we find that occupations have at least as much if not more explanatory power for earnings than education for the same number of categories (Appendix Figure A.1), and greater explanatory power when considering all available categories, confirming (i) (Appendix Figure A.2). Also in line with Acemoglu and Autor (2011) for the USA, we see that the explanatory power of occupations for earnings has risen more rapidly than that of education in recent decades in the broad LIS sample (Appendix Table A.1). This finding is consistent with evidence of a polarization in wages and employment in recent decades (Goos et al.2009, Michaels et al. 2014), implying that education is not a sufficient statistic for earnings as the evolution of earnings has become non-monotonic in the educational level (confirming (ii)).

In terms of (iii), one would expect the explanatory power of occupations to be especially high in countries with low levels of education. We do indeed find that this is the case for the 1980-90s (columns (2) and (4) in Appendix Table A.2), confirming (iii), but no longer in the 2000-10s (columns (3) and (5) in this Table). The reason is not that occupation became less important in countries with low levels of education, but that polarization and offshoring made occupations more important also in high education countries. Taking these findings together, we conclude that occupational data remain extremely important for understanding wage differentials, underscoring the relevance of the updated 2020 OWW database.

Table 1 summarizes the coverage of the sample used in this paper, which differs from the full OWW dataset available online in that it excludes the data from 21 non-sovereign countries with current populations of less than one million inhabitants (such as Falkland Islands, Gibraltar etc.) 10 The dataset has far fewer observations than if each of the remaining 171 countries had reported every occupation in all years. The reason is that most countries responded to the Inquiry intermittently and reported pay for only some occupations. On average, countries reported wages for 22 years and for 78 occupations. ${ }^{11}$ Even with the incomplete reporting by ILO member countries, the bottom rows of Table 11 show that our

\footnotetext{
${ }^{10}$ Results are robust to including them (available upon request).

${ }^{11}$ Appendix D contains a full list of the occupations, industries and countries from OWW used in this paper.
} 
sample contains 191,618 country-occupation-year data points on wages. Somewhat over half of the observations $(107,978)$ are for the 45 occupations overlap sample.

We examine several related measures of skill differentials. As the broadest summary of occupational skill premia, we use the standard deviation of log wages of occupations. This measure covers the entire distribution of reported wages in the same log wage units as human capital analysis of earnings for individual workers. We calculate standard deviations for 5 year averages of the available wage reports to smooth out measurement error and reduce the imbalance of the sample ${ }^{12}$ The left panel of Figure 1 displays the time paths of the mean of differentials for the 45 occupations that are included in the dataset before and after the expansion in all countries and in countries in the high income, medium income, and low income groups, as defined by the World Bank. The right panel presents the corresponding averages for all occupations in the dataset starting from $1980 .{ }^{13}$

Figure 1 summarizes the key pattern of change found in our data: a long-run decline of occupational skill premia, with a partial rebound starting in the 1980s. Further analyses showed that changes in the sample composition in the form of a disproporionate exiting of countries with high pay differentials decrease the sample averages in the first and last periods of the left panel in Figure $\left.1\right|^{14}$ To bring out the U-shaped pattern of skill premia in the data more clearly, we examined decade average wages for a balanced panel of countries, filling gaps in wage series of one decade by means of log-linear inter- and extrapolations as described in the note of Appendix Figure B.2. This balanced sample brings out the U-shape relation from Figure 1 more clearly. From the 1950s to the 1980s, the variance fell in 76 of the 91 countries $(84 \%)$, while increasing in 68 of them $(75 \%)$ from the 1980 s to the 2000s. 15

\footnotetext{
${ }^{12}$ Except for the 1953-54 and the 2005-2008 period averages, which are based on up to 2 and 4 wage reports, respectively.

${ }^{13}$ The average standard deviation in the early 1980s is about $0.1 \mathrm{ln}$ points larger in the right panel of Figure 1. This is due to the larger number of occupations at the upper end of the wage distribution in this sample.

${ }^{14}$ Only 64 countries are represented in the first period, and 58 countries the last period.

${ }^{15}$ The other panels of Figure B.2 show that the pattern is similar when we weight occupations by their estimated share of covered employment (see Appendix $\mathrm{C}$ for details), and when we weight each country by its population.
} 
Each country grouping follows the same pattern.

We further estimated pay differentials in particular parts of the wage/skill distribution, dividing occupations the ILO characterizes as more or less skilled in terms of the education "required" to do the work. We distinguish four skill groups: unskilled occupations that require at most primary schooling, lower medium skilled occupations that require lower secondary schooling, upper medium skilled occupations that use upper secondary education, and high skilled occupations that correspond to post-secondary education. 17 Table 1 reports the number of occupations per skill group. Using these categorizations, we find the U-shaped pattern in differentials when we consider the top or top two skill groups as "skilled" (see the top two panels of Appendix Figure B.3. At the bottom of the skill distribution, however, the 16 unskilled occupations show a continuous narrowing in the gap compared to the 146 more skilled occupations (bottom panel of Appendix Figure B.3). ${ }^{18}$

Even though the different measures show some variation, the basic pattern is one of narrowing followed by a partial rebound among occupations higher in the skill distribution. What caused the substantial narrowing and partial rebound of differentials?

\footnotetext{
${ }^{16} 14$ of 21 high income countries (67\%), 40 of 45 middle income countries (89\%), and 22 of 25 low income countries $(88 \%$ ) had declines in occupational differentials between the 1950 s-80s, while $71 \%$ of high income countries, $76 \%$ of middle income countries, and $76 \%$ of low income countries had increases between the 1980s-2000s.

${ }^{17}$ Since the ILO does not distinguish between occupations requiring lower and upper secondary education, the distinction between lower and upper medium skilled occupations is based on the typical ranking of relative wages: See Appendix B for details. Occupational wage ranks correlate highly over time (Appendix Figure B.1), implying that relative skill requirements of occupations are quite stable over the sample period. Note that while we base our assessment of the relative skill requirements of occupations on the ILO classification, there are large differences across countries in the extent to which workers with a specific education level actually work in the assigned occupations. Our supply variable takes such differences into account, see Section 3).

${ }^{18}$ This pattern is reminiscent of the finding of declining average returns to schooling, driven by declining returns to primary and secondary schooling, but increased differentials for tertiary education, by Montenegro and Patrinos (2014) in a sample of 139 countries and mostly after 1990.
} 


\section{Educational Expansion and Occupational Labor Sup- ply}

The large increase in years of schooling in all countries post World War II offers a plausible explanation for the narrowing of occupational differentials. More education would increase the supply of workers to the higher-skilled and higher-paid occupations where they presumably work, while decreasing the supply of workers in lower-skilled and lower-paid occupations.

Figure 2 displays the upward trend in schooling worldwide in terms of the average years of schooling for workers above 15 years of age. Measured by absolute years, the mean years of schooling increased by 5.3 years for all countries, with a modestly larger increase of 5.8 years for middle income countries and a smaller increase of 4.3 years for low income countries. Measured in percentage increases, however, the mean increase was largest for the low income countries due to their extremely low level of education in the initial year, and decelerated over time.

Because workers in the same occupation - say teacher or carpenter or laborer - have higher levels of schooling in advanced countries, where most persons have at least a high school degree, than in low income countries, where many persons have at most an elementary school education, increases in education have differential effects on occupational labor supplies across countries. To measure these differences requires country level information on the occupational distribution of workers by education. We obtained such data from the World Bank's I2D2 database, a collection of harmonized and nationally representative household surveys developed by Montenegro and Hirn (2009).19 I2D2 estimates the distribution of employees aged 15 to 64 in one-digit ISCO-88 occupations for four educational groups: no schooling, primary schooling, secondary schooling and post-secondary/tertiary schooling, for countries with household surveys. Absent education data for more detailed occupations, we

\footnotetext{
${ }^{19}$ We thank Kathleen G. Beegle, Claudio E. Montenegro, David Newhouse and Aditi Mishra from the World Bank for giving us access to the I2D2 data. Figures for more detailed occupations and education levels would be problematic in many countries due to the size of the surveys.
} 
develop our supply measures for occupations at the one digit level and apply those measures to our more detailed occupations within each one-digit group.

Even at the one digit occupation/four education groups level, the data show huge country differences in the distribution of workers with the same education level across occupations. In countries where few workers possess post-secondary education, many workers with secondary schooling are in professional and manager occupations. By contrast, in countries where many workers have post-secondary education, few secondary school workers obtain such jobs. For example in Honduras in 1998, where only 5 percent of employees possessed any postsecondary education, 46 percent of secondary-educated employees worked as professionals or managers whereas in the USA in 2010, where 67 percent of employees had post-secondary education, only 16 percent of employees with secondary schooling worked in professional or managerial occupations.

Figure 3 displays the general pattern across all countries. It shows that as the share of employees with post-secondary education increases, the share of professionals and managers among workers with secondary education decreases. Still, the regression of the share of professionals among secondary education workers on the national share of workers with a post-secondary education explains only a modest proportion of the cross-country variation, indicating that countries with a similar supply of post-secondary educated employees differ substantially in the allocation of workers. This illustrates the importance of having country specific education-occupation matrices to link educational attainment to occupational labor supply by country.20

We estimate occupational labor supplies in a country by applying a single country-specific education-occupation matrix to the Barro-Lee estimates of the education distribution in the country. Let $a_{i o}$ be the share of workers in education category $i$ in one digit occupation $o$

\footnotetext{
${ }^{20}$ Conversely, workers with post-secondary education have a slightly higher chance of ending up in jobs below professional and managerial occupation in countries in which many employees possess post-secondary education. However, this relationship is less robust, suggesting that as the supply of workers with postsecondary education increases, the demand for professional occupations and managers often expands at a sufficient pace to absorb them.
} 
in a country, and let $E_{i t}$ be the share of workers in education group $i$ in a period. Then, our estimate of the change in the supply of an occupation's work force relative to other occupations in the country between two periods is:

$$
\sum_{i} a_{i o} \Delta E_{i}
$$

With $a_{i o}$ fixed, shifts in the country's educational attainment distribution towards higher educated groups shift supply outward in occupations that employ relatively more educated workers, and shift supply inward in occupations that employ less educated workers. The shifts differ across countries due to different changes in the educational distribution and the different country-specific occupational employment distributions within education groups. By using a fixed education-occupation matrix to estimate the distribution of workers by education across occupations, we focus our analysis on changes in supply resulting from changes in the distribution of national education as opposed to potentially endogenous changes of the $a_{i o}$ coefficients ${ }^{21}$ We assign the change in labor supply to the occupations in our dataset based on the one digit occupation group to which they belong. This produces measurement error in the change in supply, which is likely to bias downward the estimated supply coefficients 22

We also need aggregate changes in educational attainments to be exogenous with respect to occupational wages to identify supply rather than demand effects in our analysis. One reason this is likely to be the case is that educational attainments in Barro and Lee (2013) are measured as average years of schooling among men and women aged 15 years and above so that observed changes will be the result of educational choices made over several decades. Hence, while increases in skilled wages increase the short-run incentive to invest in education among the young, the effect on $\Delta E_{i}$ will be spread out over decades. A second reason is that

\footnotetext{
${ }^{21}$ When I2D2 had more than one survey for a country we averaged education-occupation percentages across all available surveys. See Appendix C for a detailed description.

${ }^{22}$ Appendix Figure C.1 shows that around $60-69 \%$ of the wage variation between the detailed OWW occupations is related to the 9 major groups, suggesting that occupational labor supply shifts at this level will have some explanatory power.
} 
our analysis controls for GDP per worker, which is the main likely confounder for educational supply changes over long periods of time. In any case, we have confirmed the robustness of results by replacing $\ln$ GDP per worker with ln capital per worker and ln total factor productivity (TFP) as potentially more fundamental indicators of demand shifts (results available upon request). Third, while the education-occupation matrix may also be affected by occupational wages, we keep this matrix fixed over time. The observed matrix may have been influenced by previous wage shocks, but the inclusion of country-occupation fixed effects will mitigate this risk by capturing most of the within-occupation serial correlation of wage shocks in a country. Finally, to the extent that aggregate shifts in education are still correlated with unobserved demand shifts towards skilled occupations, our results will underestimate the true supply effects.

For about one-third of the countries in OWW, the I2D2 did not have household surveys from which to calculate education-occupation matrices. Rather than deleting these countries from our study, we imputed the employment distribution based on nine income-region specific averages as described in Appendix C. We probed the robustness of our supply estimates by analyzing only countries with a non-imputed employment distribution in the sample and by using only income-region country group-specific averages and obtain results similar to those in the dataset with imputed education-occupation matrices.

Table 2 summarizes the resulting estimates of supply in the form of the average proportion of the work force that would be supplied to the specified major occupations relative to the total work force in a country. ${ }^{23}$ Since each periods' labor supply is allocated to one of the main occupations, the labor supplies to the occupations sum to 100\%. Despite our deriving of the supply measure at the one digit occupational level and imputing of the educationoccupation matrices for some countries, our technique produces considerable variation in the estimated shifts of labor supply to occupations over time and across countries in different income groups.

\footnotetext{
${ }^{23}$ Since the Barro-Lee dataset contains educational attainments every 5 years starting in 1950 , we take the average of two subsequent reports as our estimate for the respective 5 year-period between both years.
} 
Taking the all country panel first, the row for the early period (1950-55) shows that the educational distribution would have put an average of $36.3 \%$ of workers into elementary occupations, compared to $9 \%$ in the three highest skill occupations- professionals, associate professionals and managers. As average schooling increased over time, the supply in elementary occupations fell to $24.4 \%$ of the work force in $2005-2010$, while the supply in the three highly skilled occupations increased from 4.1 to $9 \%$ for associate professionals, from 2.9 to $7.8 \%$ for professionals, and from 2 to $3.4 \%$ for managers. The global story is clear: the expansion of educational attainments reduced supply to less skilled occupations and increased supply to more skilled occupations across countries of all income levels.

Figure 4 shows that the estimated supply to skilled occupations exceeds the proportion of the population with post-secondary school education, whereas the estimated supply to elementary occupations falls short of the proportion of workers without any schooling. This reflects the fact that in many low-education countries, even workers without post-secondary education work in skilled occupations and are thus not employed in elementary occupations.

Do the estimated shifts in occupational supply reduce occupational wages in the more skilled occupations and increase wages in the less skilled occupations, as they should if they indeed measure the shift in supply?

\section{Estimating the Determinants of Occupational Wages}

To assess the impact of changes in supply and other factors on wages in detailed occupations, we estimate an occupational wage equation that links OWW occupation-country wages to our estimated occupation-country labor supply, GDP per worker and the trade orientation of an economy reflected in merchandise export plus imports/GDP 24 and to union density. Wages and GDP per worker are deflated to constant national prices using the Penn World Table GDP deflator. We use a log-log form for wages, supply and GDP per worker, so that

\footnotetext{
${ }^{24}$ We focus on merchandise trade because of concerns about the consistency of total trade measures (Lipsey, 2009).
} 
parameters estimate elasticities:

$$
\begin{aligned}
\log \left(w_{c o t}\right) & =\alpha+\beta_{1} \log \left(\text { supply }_{\text {cot }}\right)+\beta_{2} \log \left(G D P / w_{c t}\right) \\
& +\beta_{3} \text { union }_{c t}+\beta_{4}((X+M) / G D P)_{c t}+D_{c o}+D_{o t}+\varepsilon_{c o t}
\end{aligned}
$$

Including dummy variables for country-occupation $\left(D_{c o}\right)$ and for period-skill group $\left(D_{o t}\right)$ in equation 2 eliminates any country-occupation or global skill group-period factors. Thus, we identify the $\beta$ parameters from variation of wages within country-occupations over time.25

As noted, to deal with the fact that data on GDP per worker, trade openness and union density are at the country-level, we estimate equation 2 separately for occupations in four skill level groups: (unskilled) elementary occupations, lower medium skill occupations, upper medium skill occupations, and high skill occupations. To the extent that changes in these variables are associated with differential changes in the demand for workers with differing skills, the skill group regressions will yield different estimated coefficients for the groups that can help explain changes in differentials within countries.

Table 3 presents estimates of the impacts of the posited wage determinants on log real wages using five year-averages of all data, which gives us up to 12 time series data points for each country-occupation from the early 1950s through the late 2000s. ${ }^{26}$ Columns (1)

\footnotetext{
${ }^{25}$ We derive the estimating equation from an aggregate production function that depends on capital and an aggregate labor measure of occupational labor inputs, with occupation specific labor productivity captured by the parameter $o c c_{o}$ and with an elasticity of substitution between occupations of $\rho<1$ : $Y=A K^{\alpha}\left(\sum_{o} o c c_{o} L_{o}^{\rho}\right)^{\beta / \rho}$. Assuming wages are proportionate to the marginal product of labor up to a wedge $I_{o}$, the $\log$ wage for occupation $o$ is $\log \left(w_{o}\right)=\log (\beta)+\log (Y / L)+\log \left(\right.$ occ $\left._{o}\right)-(1-\rho) \log \left(L_{o} / L\right)+I_{o}$, where $L=\left(\sum_{o} o c c_{o} L_{o}^{\rho}\right)^{1 / \rho}$ is aggregate labor input. Occupational wages vary with average labor productivity $Y / L$ and occupation-specific labor productivity occ $_{o}$. The $\rho<1$ implies that the wage will fall as labor supply increases, and increases with occupational labor productivity. The country-occupation fixed effects pick up the time invariant part of the occupational labor productivities $o c c_{o}$, and the period-skill group fixed effects control for global labor share changes as well as residual demand shifters for the four skill groups. In this framework, trade openness can impact wages in two ways: (i) by altering effective labor supplies through the factor content of trade (i.e. increasing the effective labor supply of, for example, low skilled workers by importing goods that are primarily produced by low skill workers); or (ii) by influencing the production technology and hence occupational labor productivities $o c c_{o}$. Union density affects wages by raising the pay of unionized workers above what it otherwise would have been.

${ }^{26}$ Appendix C presents further information and summary statistics on the variables. The 1953-54 average is based on up to two wage reports, and the 2005-08 average is based on up to four wage reports.
} 
and (2) examine a sparse supply-demand model, which depends on the estimated supply of workers to the occupation from the analysis in Section 3 and GDP per worker.. Column (1) covers the 45 occupations available over the full period, while column (2) includes all 162 occupations in the OWW. The estimates in both columns show a substantial negative effect of supply on wages, with elasticities of response of wages to supplies of -0.41 and -0.32 , respectively, and a large positive effect of GDP per worker on occupational wages.

We combine these elasticities with the Table 2 estimates of changes in supply - an increase in supply in the high skilled occupations by $81 \log$ points $(=100 * \log 20.2 / 9)$ and a decline in supply in the elementary occupations of $40 \log$ points $\left(=100^{*} \log 24.4 / 36.3\right)$ that yields a net increase in the relative supply of workers to highly skilled occupations versus the least skilled occupations of 121 log points - to assess the contribution of the change in relative supply on the change in relative wages. At the elasticity of wages of -0.32 , the change in relative supply reduced the high skilled to elementary occupation premium worldwide by $39 \log$ points. At the elasticity of wages of -0.41 , the reduction in the occupation premium was $49 \log$ points. The increased supply of education thus acted to depress skill premia over the half century in the countries in our dataset much as it did in Goldin and Katz (2008)'s analysis of educational differentials in the USA.

Columns (3) and (4) present estimates that include two additional factors that might have impacted occupational skill premia independent of the increase in education and growth of GDP per worker - the ratio of trade to GDP and the rate of union density. Column (3) estimates the model on a sample which includes all country-periods with data on both trade and union density. ${ }^{27}$ The effect of supply is negative but smaller than in columns (1) and (2). Trade has an insignificant depressant effect on wages while union density has a substantial positive effect. Column (4) expands the sample by imputing values for 21 countries lacking schooling, trade/GDP or unionism data with the mean value of those variables in the

\footnotetext{
${ }^{27}$ Low income countries are underrepresented in the augmented sample for a lack of union density data, as they only represent 3 of 48 countries in this sample (alongside 24 high and 21 middle income countries). Among the 122 countries in the basic model, all income groups are well represented (29 high, 61 middle and 32 low income countries).
} 
dataset. ${ }^{28}$ The estimated effect of labor supply increases, the coefficient of trade/GDP turns positive while the coefficient on unionization remains positive and substantial. Column (5) gives results for the balanced sample of 45 identical occupations. Here too, the estimates show that education-driven increases in supply reduce wages, whereas GDP per worker and union density increase wages, while the trade variable has a negligible effect. Conditional on GDP per worker, which presumably captures any positive effects of trade via improved productivity, there is no reason to expect trade to impact wages, which lends some support to the specification.

The evidence of a substantial negative effect of labor supply at the occupation level helps explain the downward pressure on skill premia in the 1960s and 1970s. But it cannot account for the rebound of differentials that began in the 1980s. To see if the country-level demand and institutional factors can explain the rebound, we replicate the equation 2 regressions for separate groups of occupations differing in skill requirements. Differences in the estimated coefficients between the higher and lower skilled occupations provide a way to differentiate the effect of the country-level factors on more or less skilled occupations. If, say, GDP per worker has a larger impact on the wages of highly skilled workers than on the wages of less skilled workers, increases in GDP per worker could counteract the depressant effect of supply changes on wages, at least to some extent in some time periods. Estimating the equations for different groups also allows for supply to have different effects on wages for different skill groups, which further increases the potential for explaining the observed pattern of change in the occupational differentials.

Table 4 presents the results of regressing log occupational wages on their posited determinants for the four skill groups in the ILO categorization: (1) the unskilled/elementary occupations; (2) lower medium skill occupations and (3) higher medium skill occupations; and (4) high skill professional, managerial, and technical occupations. The first four columns present estimates from a specification with only supply and GDP per worker as explanatory

\footnotetext{
${ }^{28}$ We also include dummy variables for whether a variable has been imputed.
} 
variables. The -0.42 estimated supply impact for the two lowest skill groups is substantially greater than the -0.10 estimated impact for the highest skill group, which suggests the value of analyzing occupations at the bottom of the education distribution as well as the more widely studied occupations of highly educated workers. By contrast, the estimated coefficient on log GDP/worker is larger for the high skilled workers than for the low skilled worker, indicating that greater growth of GDP widened skill differentials.

Columns (5)-(8) add the trade ratio and union density variables. The addition of the trade ratio complicates the demand side of the story. The coefficients on GDP per worker are greater for the unskilled occupations, as the trade ratio variable seems to pick up the bigger demand effect on the highly skilled with a positive 0.16 coefficient for the high skill occupations compared to a near 0 coefficient for upper middle skill occupations and negative coefficients for the low and lower-medium skilled occupations - all, however, have high standard errors. Appendix Table B.2 shows that counter to the Heckscher-Ohlin prediction that increasing trade should reduce skill premia in developing countries due to their relative abundance of unskilled labor, the positive association between trade and skill premia is driven by low and middle income countries. This is consistent with the case study-evidence presented by Goldberg and Pavcnik (2007), and with recent models of the impact of trade on skill premia that stress scale effects (Epifani and Gancia, 2008), cross-border complementarities for different skill groups (Maskin, 2015) or reallocation effects towards more skill intensive firms (Burstein and Vogel, 2017).

As regards union density, the estimated coefficients show a larger union impact on the wages of workers in the elementary and lower-medium skilled occupations than on workers in the higher skilled occupations ${ }^{29}$ Given that trade openness has increased over time and unionization has fallen, the implication is that these factors contributed to the widening of skill premia in the 1980s-2000s period.

\footnotetext{
${ }^{29}$ The difference in the point estimates between the lowest and the highest skill group for trade to GDP and union density is statistically significant ( $p=0.05$ for trade to GDP, and $p=0.03$ for union density). Appendix Table B.3 shows similar results by skill group for the 45 occupation sample, except for the high skilled group for which we have only two occupations.
} 


\section{Accounting for Occupational Skill Premium Changes}

Taking the coefficients in Table 4 as our best estimate of the impact of the factors influencing occupational wages, we assess the ability of our models to account for the changing pattern of skill premia over time. To obtain the longest possible period of change, we select the two 5-year periods that are furthest apart for each country with data on at least one occupation in both periods. For occupations in the two periods, we compare the observed real wage change in log points to the change predicted from changes in log occupational labor supply and in log GDP per worker, and the period x skill group dummy coefficients. We do this by calculating a predicted late period wage as the sum of the actual early period wage and the point estimates from Table 4, multiplied by the changes in the respective variable between both periods. Our "predicted wage change" is the difference between this predicted late period wage and the actual early period wage. Put differently, our prediction answers the question: "Given the changes in the explanatory variables between the early and the late period and our regression point estimates, how would we expect the early wages to change?"30

Figure 5 shows the results of this calculation in terms of the ability of the average predicted log wage change to explain the average observed log wage change, country by country. The model with labor supply and GDP per worker is relatively successful at predicting wage changes, with a regression coefficient of observed log changes on predicted log changes close to one and an R2 of $0.48{ }^{31}$ Given this pattern, we assess next how well the model predicts changes in the wage premium for skilled occupations by country. To obtain country-level skill premia, we identify occupations in the top two skill groups as "skilled" and occupations in the bottom two skill groups as "unskilled", and calculate a skilled-unskilled premium as $100^{*}$ (average log skilled wage-average log unskilled wage) for each country. ${ }^{32}$ Since this

${ }^{31}$ Giving more weight to more precisely estimated wage level changes by weighting the countries by the square root of the number of underlying wage reports increases the R2 slightly to 0.52.

${ }^{32}$ We focus on the skilled-unskilled premium since it gives us greater leeway to take account of the differential effect of country-level variables in contributing to the pattern, based on the Table 4 regression results. However, the pattern of narrowing followed by partially rebounding skill premia occurs in both the standard deviation of ln wages and the skilled-unskilled premium, cf. Appendix Figures B.2 and B.3.
} 
procedure requires occupations from both skill groups in each period, we exclude the $20 \%$ of country-periods with the fewest wage reports by skill group. This reduces modestly the number of countries and the average distance between the selected early and the late period, while raising the correlation between actual and predicted skill premium changes. Including these observations gives similar results to those in the text (results available upon request).

Panel A of Table 5 summarizes the results. Columns (1) and (2) show that the model predicts a decline of $6 \log$ points in the average skill premium, whereas the actual decline was $4.7 \log$ points over the full period ${ }^{33}$ The correlation between the actual and predicted skill premium changes at the country-level is significant, though noisier than the correlation of changes in wages by occupation (see Appendix Figure B.4), as looking at changes in skill premia differences out common patterns of change shared by both skilled and unskilled occupations in a country. Columns (3)-(5) break down the predicted change into the contributions of changes in supply, skill group x period dummy coefficients, and GDP per worker. Over the full period, occupational labor supply changes pushed down the average skill premium by $11.3 \log$ points, which the increase in log GDP per worker only partly offset, despite an increase of more than $100 \log$ points ${ }^{34}$ The bottom row of panel A shows that the skill premium-reducing supply effect is both due to increased supplies in skilled occupations $(+33.4 \log$ points), and decreased supplies in unskilled occupations $(-9.7 \log$ points $)$.

To account for the U-shape, our models must predict a turnaround in skill premia for the two post-1980 periods that are furthest apart for each country and that also have a sufficient number of skilled and unskilled wage reports in both periods. The average selected early period is 1985-89, and the average selected late period is 2000-2004. Panel B of Table 5shows that the average skill premium (scaled to a 25 year period) increased by $10.5 \log$ points, of

\footnotetext{
${ }^{33}$ We scale the averages to a 55 year period, which corresponds to the approximate distance between the mid-points of the first and last sample period.

${ }^{34}$ We examined the robustness of the Table 5 results to different weightings of observations: (1) weighting the skill premium changes by the geometric mean of the square roots of the number of wage observations that went into the cross country averages, on the notion that changes based on more occupations are more reliable; and (2) weighting occupations by their employment share in the average skilled and unskilled wages within countries, using employment weights per Appendix Section C. We obtained results similar to those in Table 5 (available upon request).
} 
which the model predicts 6.7 log points. Columns (3)-(4) show that supply pushed down skill differentials by $-6.6 \log$ points in the post-1980 period. Working in the opposite direction, the coefficients of the period $\mathrm{x}$ skill group dummies increased for the skilled occupations to raise skill differentials by 9.9 log points. By contrast, increases in GDP per worker are associated with a decreasing skill premium, reflecting the stronger effect of GDP per worker on the lower skilled wages in the full model.

Columns (6) and (7) give calculations for our model which includes changes in trade to GDP and union density. The results suggest that these factors contributed to the post-1980 U-turn in skill differentials. Trade to GDP increased on average by 25.8 percentage points, which translates into an estimated increase of skill premia by 6.3 log points, whereas union density declined by 21.7 percentage points, translating into an increase of skill differentials by $5.3 \log$ points.

Figure 6 plots the observed skill premium changes on the vertical axis against four different sets of predicted skill premium changes on the horizontal axis, always for the same sample. In the top left panel, which predicts changes in the basic model, we find an insignificant association with the observed changes. In the next two panels, which include changes in trade/GDP or union density in the prediction, the association between actual and predicted skill premium changes strengthens to produce an R2 of $0.17-0.29$. The association is strongest in the last panel where we include both trade to GDP and union density, giving an $\mathrm{R} 2$ of $0.42 .^{35}$ Thus, taken together, changes in trade to GDP and union density account for the entire observed net increase in the average skill premium after 1980, and are also strong predictors of skill premium changes at the level of the individual countries. As our estimated trade effect likely reflects the impact of unmeasured factors correlated with increasing trade opennes: ${ }^{36}$ and our estimated union density effect likely reflects spill-overs of declining union

\footnotetext{
${ }^{35}$ Results for the post 1980 -sample are similar if we count the upper medium skilled occupations as "unskilled" instead of as "skilled" (results available upon request).

${ }^{36}$ Replacing ln GDP per worker with ln capital per worker and ln TFP as potentially more fundamental indicators of the factors driving wages does not weaken the effects found for trade and union density (results available upon request).
} 
density on the wages of non-unionized workers, we view these variables as "representative" of changes in the trade and institution domains that contributed to the increase of skill premia after 1980 that occurred in most countries.

\section{Conclusion: Learning from Occupational Skill Premia, Past and Future}

The literature has documented an increase in skill premia in many high income countries after 1980 (Autor, 2014), but evidence for developing countries is scarce. Comparable data series often only start after 1980. In this paper, we use newly available occupational wage data to show that these increases in occupational skill premia broke three or so decades of declining premia in a majority of countries at all income levels. Our analyses suggest that this narrowing was due in part to the huge worldwide increase in the supply of educated workers that continued to push down skill premia after 1980, but was more than offset by other factors widening skill premia. On a descriptive level, our global account hence mirrors the one by Goldin and Katz (2009) for the USA in the sense that education has "lost the race" against these other factors after 1980.

While a rigorous decomposition of these "other factors" is beyond the scope of this paper, our findings point to the difficulty of any simple single factor-explanation to account for this increase. Accounts that focus exclusively on skill-biased technological change completely miss the strong within country-correlations of changes in trade openness and union density with changes in skill premia that the data show. The trade result is consistent with the review by Goldberg and Pavcnik (2007) and an increased recognition that increasing openness tends to increase skill premia. The union result is consistent with the finding that unions reduce pay differentials in both advanced and developing economies (Freeman, 1998).

Did the U-shaped change in differentials found in the OWW persist after 2008 when the ILO terminated its October Inquiry of wages, or did occupational differentials move in a 
different direction in succeeding years? As no organization or statistical agency has gathered detailed occupational wage data for countries around the world, we answer this question by examining more aggregate occupational wage data from the ILO and from the Union Bank of Switzerland that come closest to the Inquiry data.

Calculating the change in skill differentials in the ILOSTAT and UBS data in a similar way as we calculated the OWW skilled-unskilled premium, we find that both sources show declining skill differentials in a slight majority of countries from 2008 to $2017{ }^{37}$ This pattern is consistent with what changes in our main drivers would predict for the period. Union density continued to decline after 2008 at an average rate of 3.2 percentage points per decade, pushing up the skill premium, while the ratio of merchandise trade to GDP declined at a rate of 5.6 percentage points per decade, pushing down the skill premium. Weighting these changes by the Table 4 estimated effect of the two variables on wages suggests that differentials should have narrowed modestly even absent the continued expansion of education, which would further reduce skill differentials. ${ }^{38}$ Thus the post-2008 reductions in occupational skill differentials weakened the U-turn that began in the 1980s but were neither as strong nor as wide-spread as to nullify it.

Finally, while modern forms of digital data have outmoded the survey design and statistical procedures by which the ILO obtained its October Inquiry data, we believe that there is a strong case for seeking a new source of data on more detailed occupations worldwide. Such data would contribute to understanding two of the biggest areas of concern in economics in recent years: the increase of inequality in individual incomes and the impact of technology on the future of work. On the inequality side, measures of pay in detailed occupations offer

\footnotetext{
${ }^{37}$ See Appendix Table B.1. This is mostly driven by middle and high income countries, which the ILOSTAT and UBS surveys also cover most extensively.

${ }^{38}$ In the Cohen and Leker (2014) database, average schooling increases increased at an average rate of 0.85 years of schooling between 1960 and 2010, and at a rate of 0.94 years in the same countries between 2010 and 2020. The trend estimates for trade and union density come from a regression of all available data for the 2009-2017 period on country dummies and a trend and are highly significant, with standard errors clustered at the country level. To translate the trade and union density point estimates for the four skill groups in Table 4 into changes for the two coarse skill groups introduced in Section 5 , we take the weighted average of point estimates, using the number of occupations per sub-group as weight.
} 
a lens into the underpinnings of the increased within country inequality in incomes - the extent to which this inequality reflects the divergence or polarization of income between skilled and unskilled work. ${ }^{39}$ On the technology side, current analyses of the future of work focus almost exclusively on data on employment in occupations, classified by job tasks and the likelihood that machines will automate routine tasks.

Analytically, in both areas, absence of wage data for detailed occupations and the possibility of inferring "shadow wages" for particular tasks makes it difficult to disentangle the shifts in supply from shifts in demand that invariably show up in both the quantity (occupational employment) and price (occupational wages) side in the market 40 Data on wages at a high level of occupational detail across countries, perhaps from internet surveys of firms and/or workers, with information on the job tasks and work activities in occupations in different countries, would improve our ability to infer from shifts in the value of tasks and work activities where technology has its bite. Analyses of labor markets would benefit greatly from a renewed effort to obtain such data updated to salient modern occupations.

\section{References}

Acemoglu, D. and Autor, D. (2011). Skills, Tasks and Technologies: Implications for Employment and Earnings. In Handbook of Labor Economics, volume 4b. Elsevier, North-Holland.

Acosta, P., Cruces, G., Galiani, S., and Gasparini, L. (2019). Educational upgrading and returns to skills in Latin America: evidence from a supply-demand framework. Latin American Economic Review, 28(1):18.

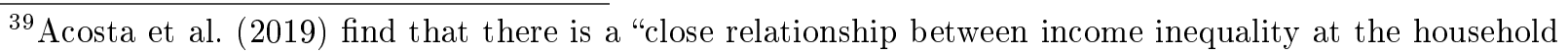
level and the dispersion in wages, proxied by the wage gap between skilled and unskilled labor" (p. 5) in a large number of Latin American countries between 1991 and 2013.

${ }^{40}$ For instance, see Kunst (2019), who combines occupational employment with OWW wage data to document a decline in the demand for skilled production worker tasks in manufacturing around the world since the 1950s due to automation.
} 
Ashenfelter, O. (2012). Comparing real wage rates. American Economic Review, 102(2):617642.

Autor, D., Levy, F., and Murnane, R. J. (2003). The skill content of recent technological change: An empirical exploration. Quarterly Journal of Economics, 118(4):1279-1333.

Autor, D. H. (2014). Skills, education, and the rise of earnings inequality among the "other 99 percent". Science, 344(6186):843-851.

Autor, D. H. and Handel, M. J. (2013). Putting tasks to the test: Human capital, job tasks, and wages. Journal of labor Economics, 31(S1):S59-S96.

Barro, R. J. and Lee, J. W. (2013). A new data set of educational attainment in the world, 1950-2010. Journal of Development Economics, 104:184-198.

Bessen, J. (2015). Learning by doing: the real connection between innovation, wages, and wealth. Yale University Press.

Burstein, A. and Vogel, J. (2017). International trade, technology, and the skill premium. Journal of Political Economy, 125(5):1356-1412.

Cohen, D. and Leker, L. (2014). Health and education: Another look with the proper data. Mimeo.

Epifani, P. and Gancia, G. (2008). The skill bias of world trade. The Economic Journal, 118(530):927-960.

Feenstra, R. C., Inklaar, R., and Timmer, M. P. (2015). The next generation of the Penn World Table. American Economic Review, 105(10):3150-3182.

Freeman, R. B. (1998). War of the models: which labour market institutions for the 21st century? Labour Economics, 5(1):1-24. 
Freeman, R. B. and Oostendorp, R. (2000). Wages around the world: Pay across countries and occupations. Technical report, NBER Working Paper 8058.

Freeman, R. B. and Oostendorp, R. (2001). The occupational wages around the world data file. International Labour Review, 140(4):379-401.

Freeman, R. B. and Oostendorp, R. (2020). The Occupational Wages around the World 1953-2008 Database. https://data.nber.org/oww/.

Goldberg, P. K. and Pavcnik, N. (2007). Distributional effects of globalization in developing countries. Journal of Economic Literature, 45(1):39-82.

Goldin, C. and Katz, L. F. (2009). The race between education and technology: The evolution of U.S. educational wage differentials, 1890 to 2005. Technical report, NBER Working Paper No. 12984.

Goldin, C. D. and Katz, L. F. (2008). The race between education and technology. Harvard University Press.

Goos, M., Manning, A., and Salomons, A. (2009). Job polarization in Europe. American Economic Review, 99(2):58-63.

Hammar, O. and Waldenström, D. (2019). Global earnings inequality, 1970-2018. Technical report, Uppsala University and Research Institute of Industrial Economics.

ILO (2019). ILOSTAT database. https://ilostat.ilo.org/. Retrieved on June 13, 2019.

ILO (2021). Conceptual framework of isco-88. data retrieved in February 2021.

Kunst, D. (2019). Deskilling among manufacturing production workers. Technical report, Tinbergen Institute Discussion Paper 19-050/VI. 
Lipsey, R. E. (2009). Measuring international trade in services. In Reinsdorf, M. B. and Slaughter, M. J., editors, International trade in services and intangibles in the era of globalization. University of Chicago Press.

Luxembourg Income Study Database (2020). http://www.lisdatacenter.org (multiple countries; 1980-2018). Luxembourg: LIS.

Maskin, E. (2015). Why haven't global markets reduced inequality in emerging economies? World Bank Economic Review, 29(suppl 1):S48-S52.

Michaels, G., Natraj, A., and Van Reenen, J. (2014). Has ICT polarized skill demand? Evidence from eleven countries over twenty-five years. Review of Economics and Statistics, $96(1): 60-77$.

Montenegro, C. E. and Hirn, M. L. (2009). A new disaggregated set of labor market indicators using standardized household surveys from around the world. Technical report, World Bank, World Development Report Background Paper.

Montenegro, C. E. and Patrinos, H. A. (2014). Comparable estimates of returns to schooling around the world. Policy Research Working Paper Series.

Perlman, R. (1958). Forces widening occupational wage differentials. Review of Economics and Statistics, pages 107-115.

Reder, M. W. (1955). The theory of occupational wage differentials. American Economic Review, 45(5):833-852.

Roser, M. and Ortiz-Ospina, E. (2016). Global education. Our World in Data. https://ourworldindata.org/global-education.

Union Bank of Switzerland (2018). UBS prices and earnings survey 2018. https://www. ubs.com/microsites/prices-earnings/en/. Retrieved on June 10, 2019. 
Visser, J. (2019). ICTWSS database. version 6.0. http://uva-aias.net/en/ictwss. Amsterdam: Amsterdam Institute for Advanced Labour Studies (AIAS), University of Amsterdam. June 2019.

World Bank (2019). World Development Indicators. https://databank.worldbank.org/ reports .aspx?source=world-development-indicators. Data retrieved in March 2019. 


\section{Figures and Tables}

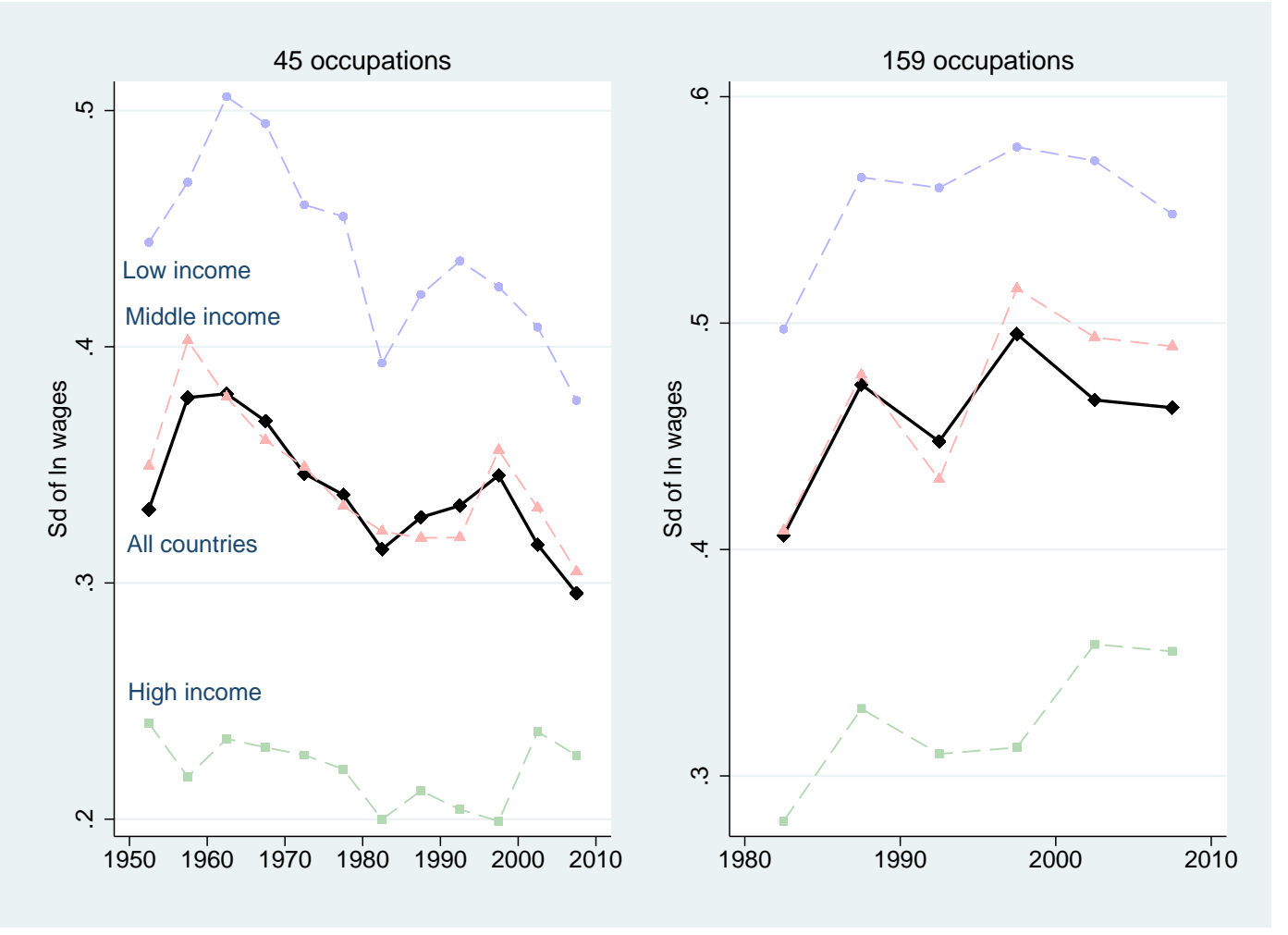

Figure 1: Evolution of Occupational Skill Premia for the 45 Occupations available for the 1953-2008 Period, and the 159 Occupations available for the 1983-2008 Period

The Figure plots the (unweighted) cross-country average standard deviation of ln wages, for the full sample and by income group. The standard deviations are calculated either for up to 45 occupations available throughout the full period (left panel) or for up to 159 occupations available from 1983 onwards (right panel). The number of different countries across which average standard deviations are calculated differs by period, depening on data availability in OWW. In the left panel, a total of 170 countries enter in at least one period (ranging between 58 and 119 countries per period). In the right panel, a total of 157 countries are represented (ranging between 58 and 109 countries per period). The income groups follow the World Bank's income group assignment in 1990. See Appendix $\mathrm{D}$ for a list of countries respresented in OWW by income group. 


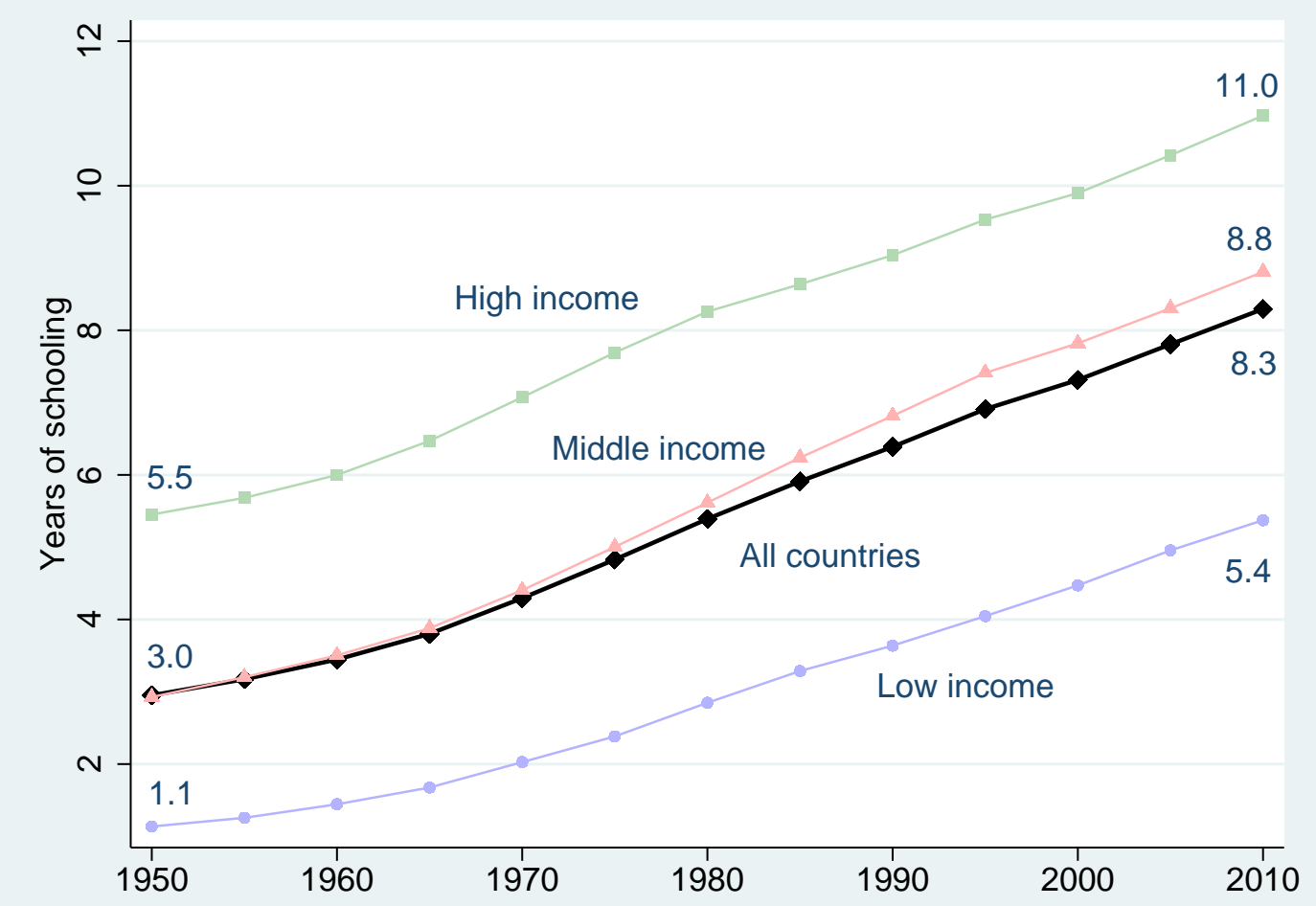

Figure 2: Evolution of average Years of Schooling

Average years of schooling of the population above 15 years, taken from the Barro-Lee dataset. Averages are calculated for the 139 countries which are represented in both Barro-Lee and OWW. 


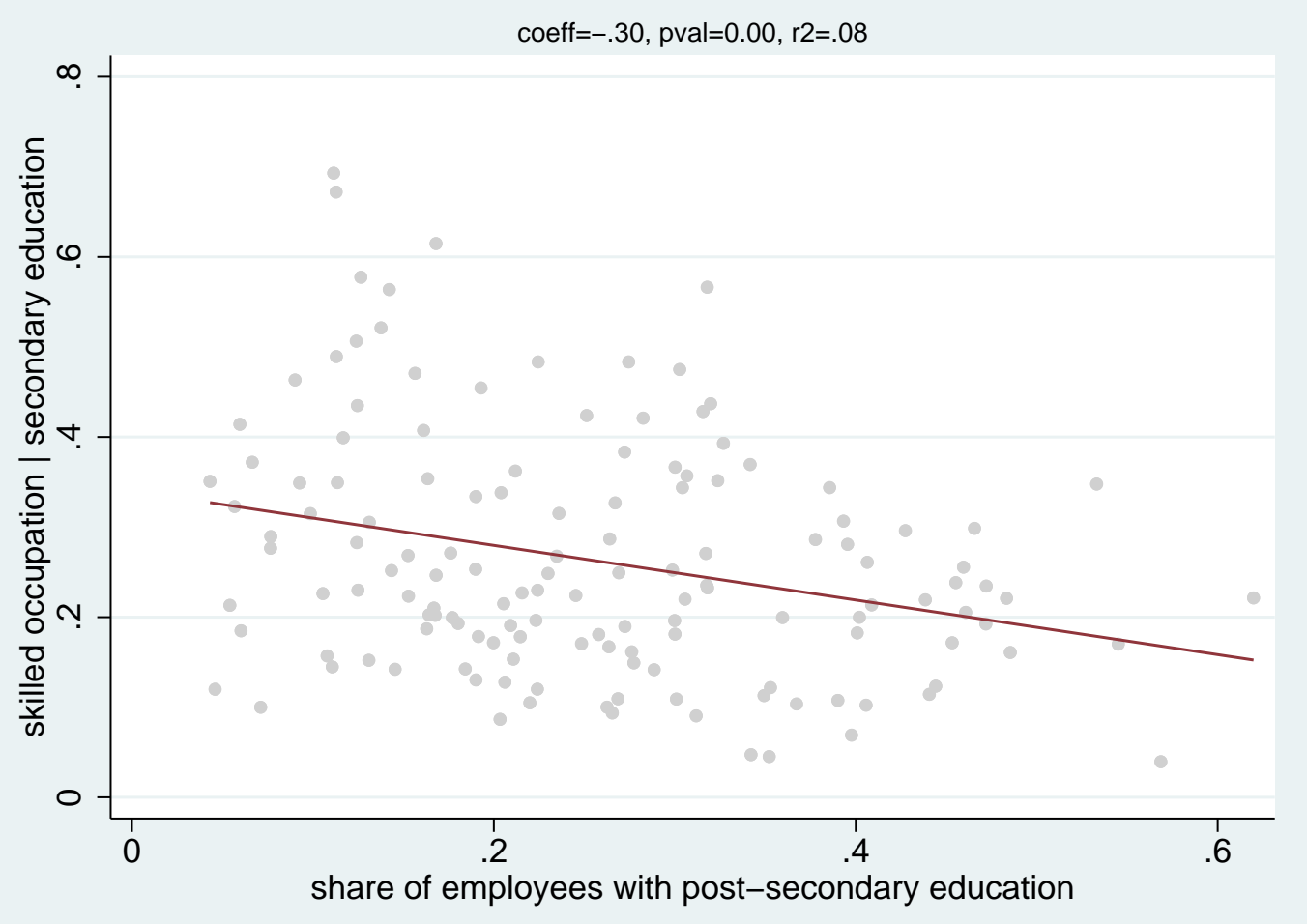

Figure 3: The Share of Secondary-educated in Skilled Occupations and the Supply of Postsecondary Educated Workers

Skilled occupations include major groups 1-3 (managers, professionals, and associate professionals). The Figure shows averages across all I2D2 surveys of a country, using the square root of the number of observations with the respective education level as weight if several surveys ar available. The red line shows the linear fit, and the title presents the associated coefficient, p-value and R-squared of the regression. 


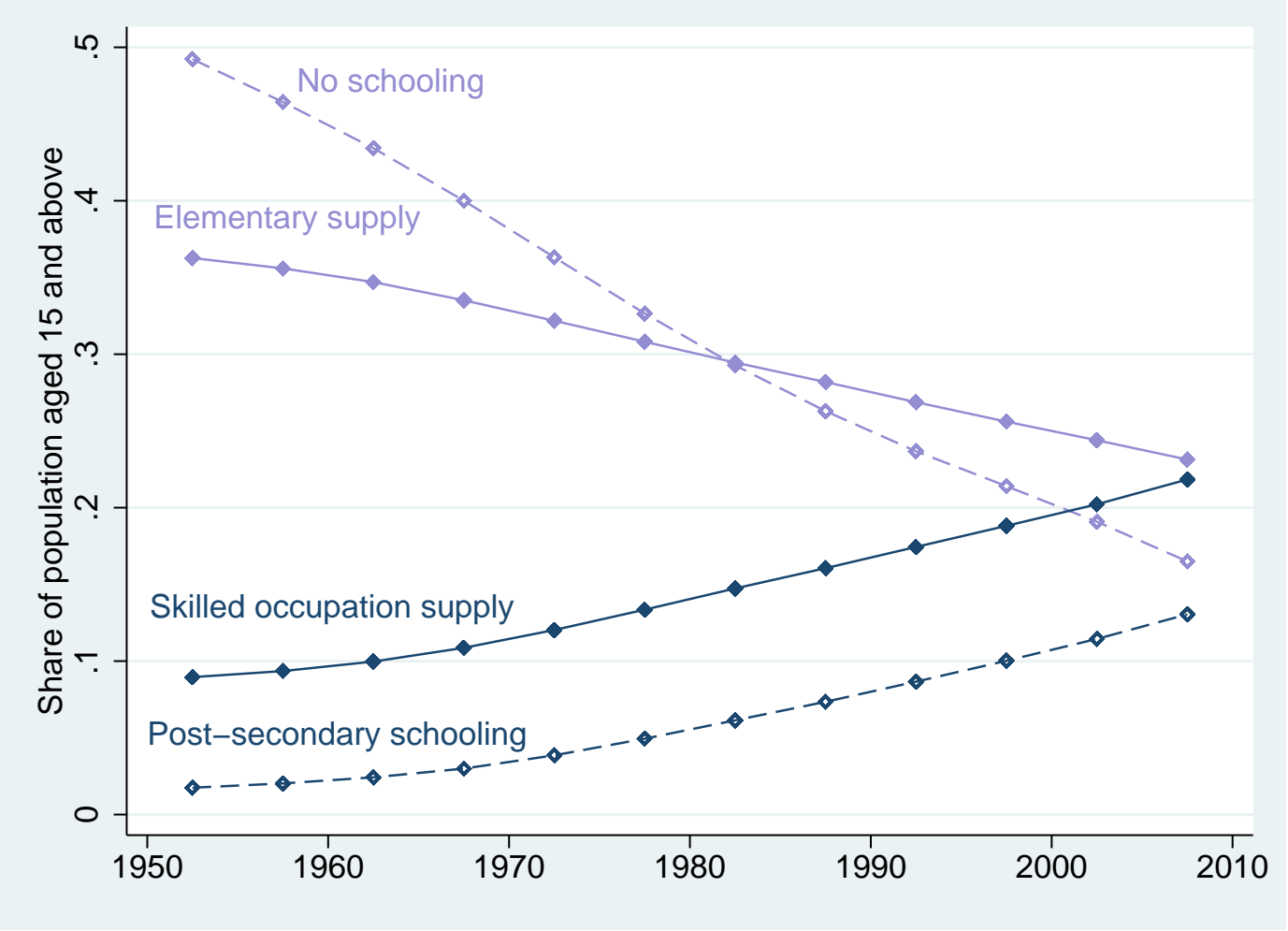

Figure 4: The Share of Workers without Schooling vs. the Estimated Supply to Elementary Occupations, and the Share of Workers with Post-secondary Schooling vs. the Estimated Supply to Skilled Occupations

Averages for the 139 countries represented in both Barro-Lee and OWW. Elementary occupations correspond to major group 9, skilled occupations to major groups 1-3. The education series are taken directly from Barro-Lee, and the occupational labor supplies are estimated based on the Barro-Lee educational attainments and the distribution of employees by level of education across major groups, as described in Section 3 . 


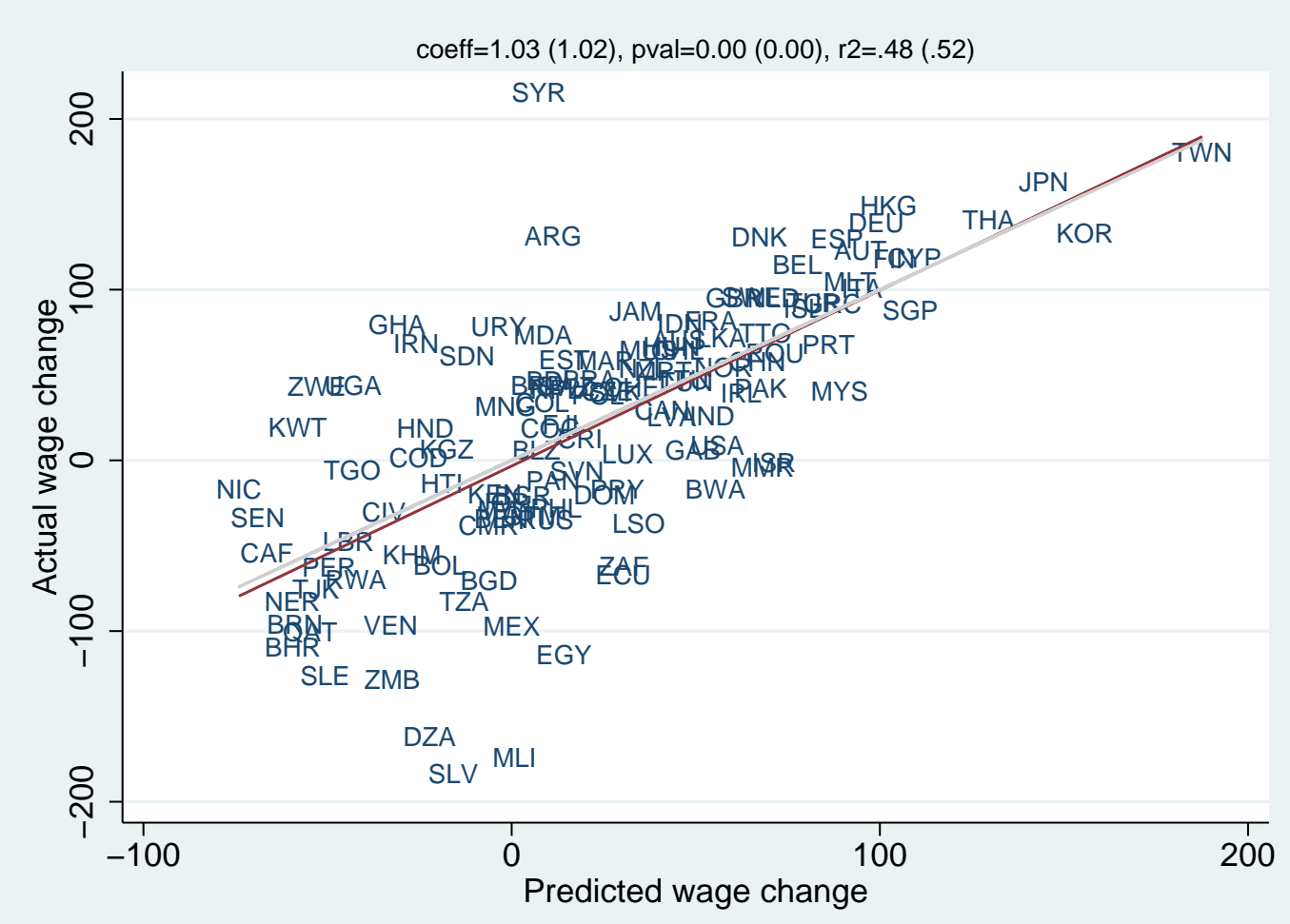

Figure 5: Comparing the Actual Wage Changes over the Full Sample Period to the Predicted Changes

For the 122 countries in column (2) of Table 3 the Figure compares the actual average real wage change between the first and the last period in the sample to the wage change that would be predicted based on the change in log occupational labor supply, the period $\mathrm{x}$ skill group dummy coefficients, and log GDP per worker. The average "early" period is 1960-64, and the average "late" period is 1995-99, so that the average period over which changes are calculated is around 35 years. The title presents the results from a regression of actual on predicted wage changes. In brackets are the results from the same regression in which we weight wage changes from each country with the square root of the number of occupations based on which the average wage change has been calculated, to give more weight to more precisely estimated wage level changes. On average, changes are calculated based on 34 occupations. 


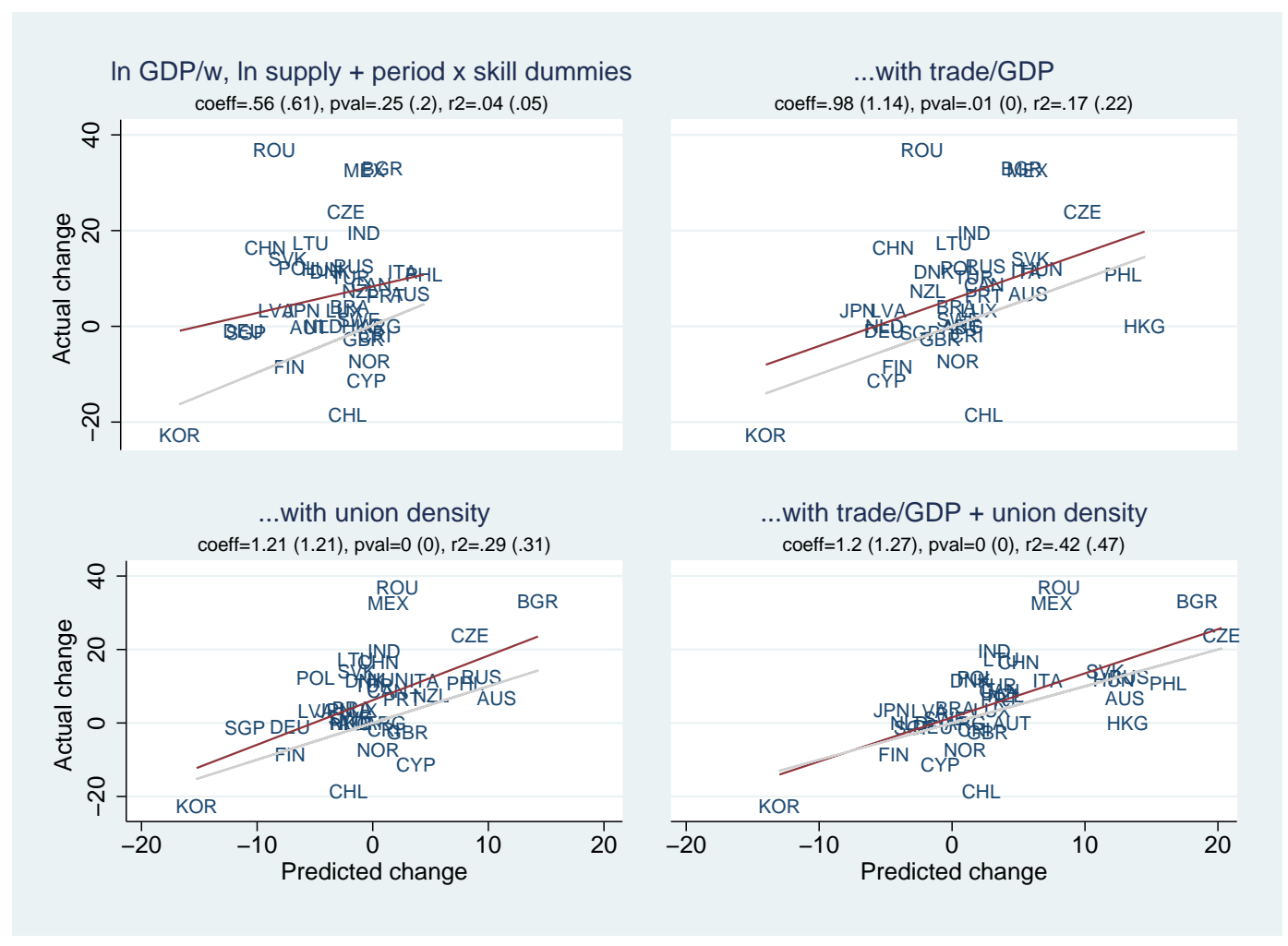

Figure 6: Comparing the Actual Changes of the Skilled-Unskilled Premium within 1980-2008 to the Changes Predicted by Factors

The Figures plot the simulation results that are also summarized in panel B of Table 5 . The top left Figure compares the actual skilled-unskilled wage premium change between both periods with the change that would be predicted from only taking into account variation in log supply, the skill group $\mathrm{x}$ period dummies, and ln GDP per worker. The further panels also take into account changes in trade/GDP, union density, and in both variables jointly for the prediction of wage premium changes. The title presents the results from a regression of actual on predicted wage premium changes. In brackets are the results from the same regression in which we give more weight to more precisely estimated wage premium changes, by weighting the wage premium changes from each country with the geometric mean of the square root of the number of skilled and unskilled occupations based on which it has been calculated. 
Table 1: The Occupational Wages around the World 1953-2008 Database

\begin{tabular}{llll}
\hline & Full Sample & \multicolumn{2}{c}{ Occupation available... } \\
& & ..throughout & ..from 1983 \\
\hline First year & 1953 & 1953 & 1983 \\
Last year & 2008 & 2008 & 2008 \\
\hline Occupations & 162 & 45 & 159 \\
- unskilled & 16 & 8 & 14 \\
- lower medium & 74 & 25 & 73 \\
- upper medium & 37 & 10 & 37 \\
- high skilled & 35 & 2 & 35 \\
Industries & 39 & 16 & 39 \\
\hline All countries & 171 & 170 & 153 \\
- high income & 30 & 30 & 28 \\
- middle income & 90 & 89 & 81 \\
- low income & 51 & 51 & 151 \\
- sovereign & 169 & 168 & 118,755 \\
\hline Wage reports & 191,618 & 107,978 & 8.6 \\
\hline Years with reports by country & & & 7.7 \\
- average & 21.8 & 21.6 & 103.9 \\
- standard deviation & 15.4 & 15.3 & 36.8 \\
Reported occupations & & & \\
- average & 78.1 & 33.7 & 9 \\
- standard deviation & 44.2 & & \\
\hline \hline
\end{tabular}

The occupations can be matched to the "International Standard Classification of Occupations" (ISCO-88) at the four digit-level, and to the 'International Standard Industrial Classification of all Economic Activities' (ISIC-88) at the two to four digit level. 3 occupations were only included in the survey between 1953 and 1982, and 114 occupations only from 1983 onwards. The middle column presents data on the sample of 45 occupations for which we have data over the full 1953-2008 period, and the right column presents the sample from 1983 onwards. See Appendix D for a detailed description of the occupation, industry and country coverage. The sample coverage in Sections 4 and 5 differs according to the availability of covariates and price level estimates from the Penn World Table for the conversion to real wages. The full OWW database includes data from an additional 21 non-sovereign countries with current populations of less than one million, and two additional occupations since it distinguishes between the "industrial chemicals" and "other chemical products" industries for two occupations. 


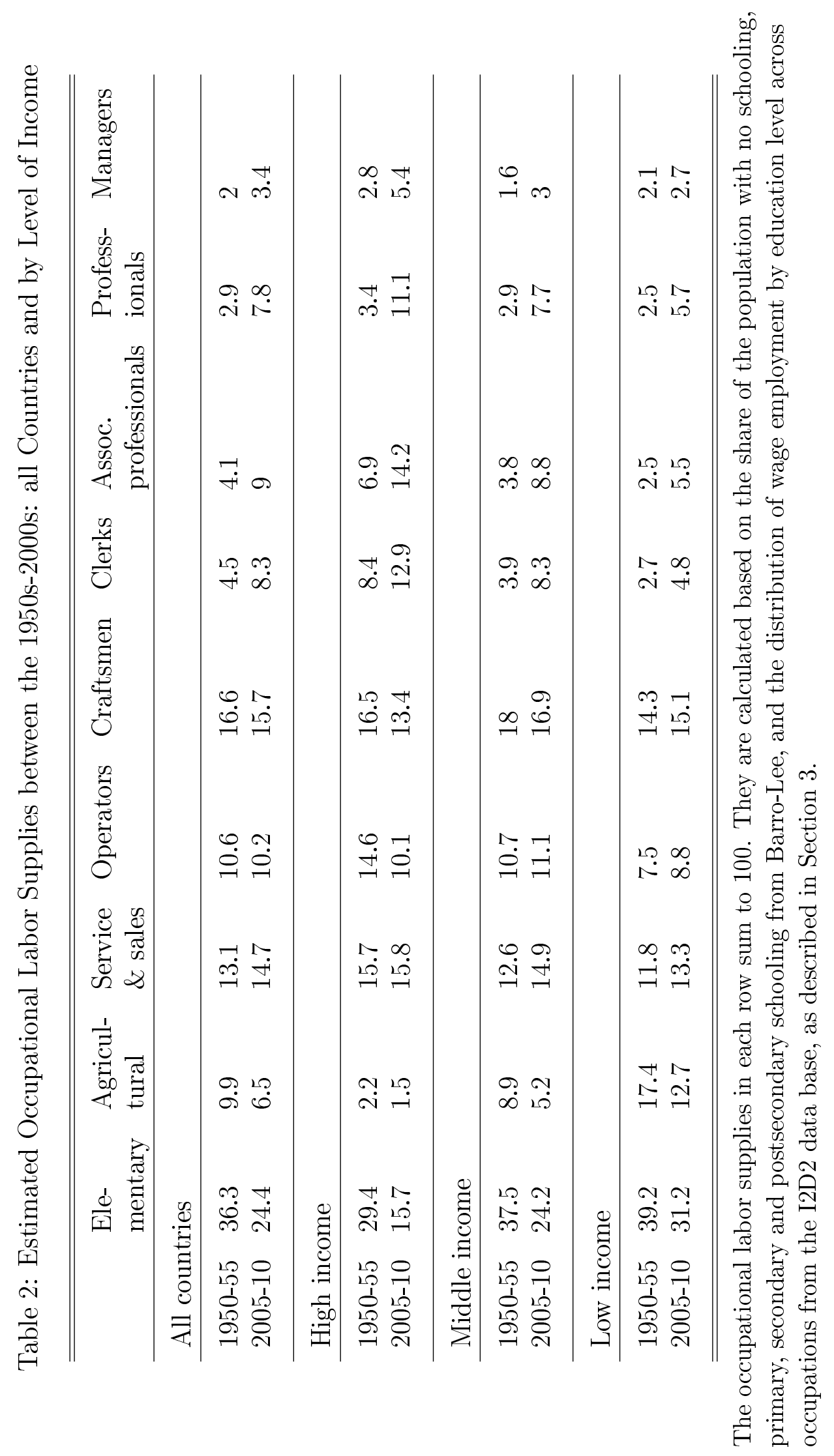


Table 3: Regression Estimates of the Determinants of Occupational Wages: Basic model and Augmented Model with Trade/GDP and Union density

Dependent variable: ln real wage

\begin{tabular}{lccccc}
\hline \hline & $(1)$ & $(2)$ & $(3)$ & $(4)$ & $(5)$ \\
\hline ln supply & $-0.41^{* *}$ & $-0.32^{* *}$ & $-0.17^{*}$ & $-0.22^{* *}$ & $-0.21^{+}$ \\
& $(0.10)$ & $(0.08)$ & $(0.07)$ & $(0.05)$ & $(0.11)$ \\
ln GDP/worker & $0.79^{* *}$ & $0.76^{* *}$ & $0.85^{* *}$ & $0.75^{* *}$ & $0.93^{* *}$ \\
& $(0.07)$ & $(0.07)$ & $(0.13)$ & $(0.07)$ & $(0.13)$ \\
trade/GDP & & & -0.09 & 0.14 & -0.27 \\
& & & $(0.13)$ & $(0.09)$ & $(0.16)$ \\
union density & & & $0.36^{+}$ & $0.31^{+}$ & $0.39^{*}$ \\
& & & $(0.19)$ & $(0.16)$ & $(0.17)$ \\
\hline Country-occup. FE & $\checkmark$ & $\checkmark$ & $\checkmark$ & $\checkmark$ & $\checkmark$ \\
Period x skill group FE & $\checkmark$ & $\checkmark$ & $\checkmark$ & $\checkmark$ & $\checkmark$ \\
Countries & 121 & 122 & 48 & 143 & 48 \\
Occupations & 45 & 162 & 162 & 162 & 45 \\
Industries & 16 & 39 & 39 & 39 & 16 \\
Intervals & 5 year & 5 year & 5 year & 5 year & 5 year \\
R2 (within) & 0.33 & 0.27 & 0.53 & 0.25 & 0.64 \\
Observations & 28103 & 51113 & 19787 & 57065 & 8755 \\
\hline \hline
\end{tabular}

Standard errors in parentheses, clustered at the country level. ${ }^{+} p<0.1,{ }^{*} p<0.05,{ }^{* *} p<0.01$. Columns (1) and (2) present the results for the basic model, for the sample of 45 consistently reported and all occupations. Columns (3)-(5) present results for specifications that include merchandise trade/GDP and union density. In column (4), missing covariates have been set to the sample mean, and the regression includes a dummy variable for each covariate that takes a value of one for such observations (not shown). Trade data are available for 140 of the 143 countries, occupational labor supply data for 122 , and union density for 53 countries. Merchandise trade/GDP is taken from the World Development Indicators, union density from Visser (2019), and all other variables (including the GDP deflator used for the conversion to real wages) are taken from the Penn World Table 9.0 (Feenstra et al. 2015). Column (5) includes only the 45 consistently reported occupations. Note that data on trade/GDP and union density are only available from 1960 onwards, so that the models in columns (3) and (5) do not include observations from the 1950s. 


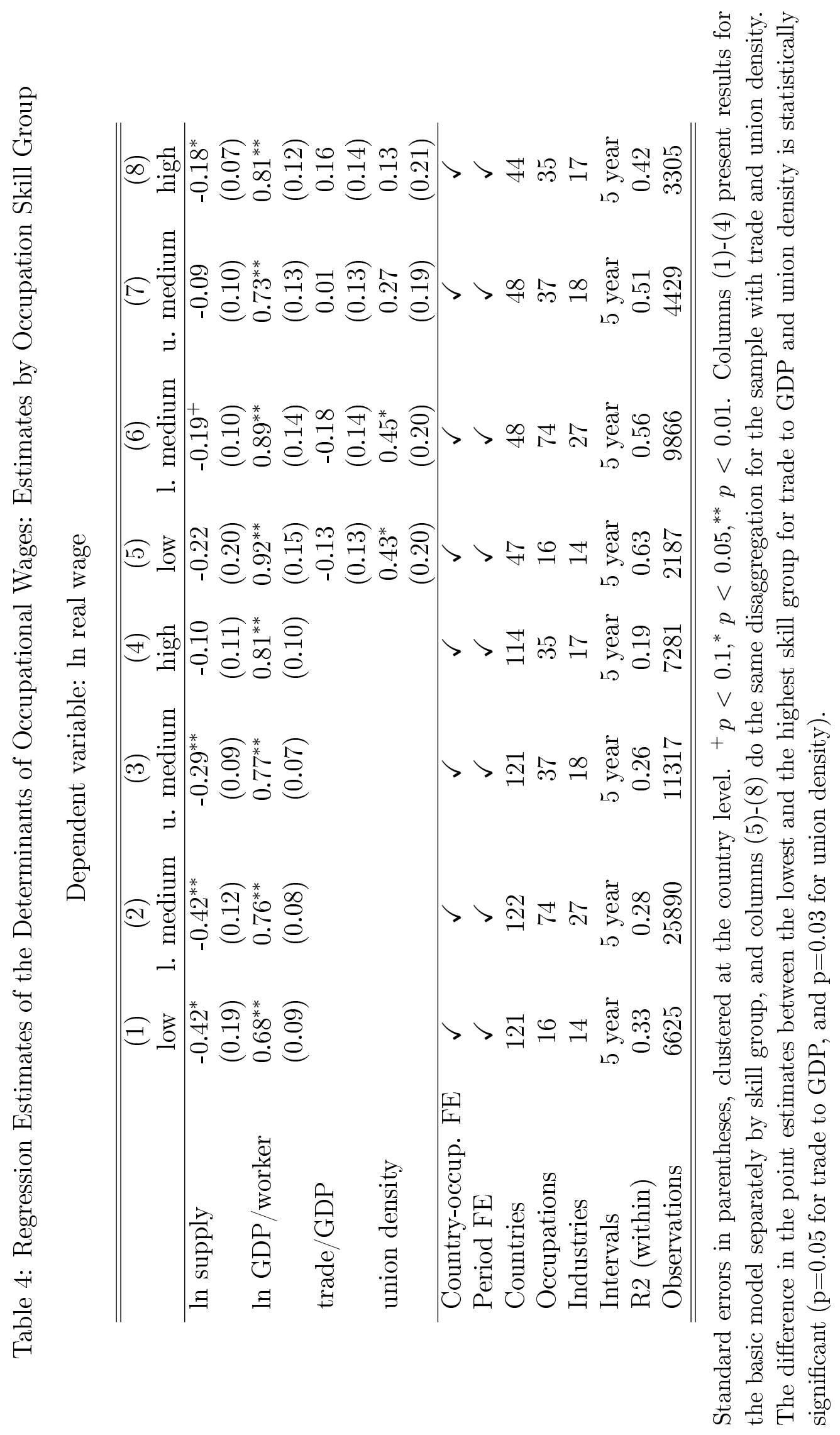


Table 5: The Estimated Impact of Changes in Supply, Demand, and Union Density on Changes in Skilled-Unskilled Premia

\section{Panel A: Narrowing of differentials, 1950s-2000s}

Changes from 1950s-2000s: Contribution of change in factor to change of skilled-unskilled premium:

\begin{tabular}{llllllc}
\hline$(1)$ & $(2)$ & $(3)$ & $(4)$ & $(5)$ & $(6)$ & $(7)$ \\
Actual & From model & ln supply & Period $x$ skill dummies & ln GDP/w & Trade/GDP & Union density \\
-4.7 & -6 & -11.3 & 1.6 & 3.7 & - & - \\
\hline \multicolumn{7}{c}{ Change of factors: } \\
\hline
\end{tabular}

Panel B: Widening of differentials, 1980s-2000s

Changes from 1980s-2000s: Contribution of change in factor to change of skilled-unskilled premium:

\begin{tabular}{|c|c|c|c|c|c|c|}
\hline (1) & $(2)$ & $(3)$ & (4) & $(5)$ & (6) & $(7)$ \\
\hline Actual & From model & ln supply & Period $x$ skill dummies & $\ln G D P / w$ & Trade/GDP & Union density \\
\hline 10.5 & 6.7 & -6.6 & 9.9 & -8.1 & 6.3 & 5.3 \\
\hline & & Change of factor & & & & \\
\hline & & $\begin{array}{l}\text { ln skilled supply } \\
20.9\end{array}$ & $\begin{array}{l}\text { ln unskilled supply } \\
-14.2\end{array}$ & $\begin{array}{l}\ln G D P / w \\
61.5\end{array}$ & $\begin{array}{l}\text { Trade/GDP } \\
25.8\end{array}$ & $\begin{array}{l}\text { Union density } \\
-21.7\end{array}$ \\
\hline
\end{tabular}

The estimates in panel A are based on the specifications in columns (1)-(4) of Table 4. The first row compares the actual and the predicted average change of the skilled-unskilled premium in the sample, scaled to a 55 year-period, as well as how changes in ln supply, the period x skill group dummies and ln GDP/worker contribute to the prediction. The second row shows the underlying changes in the average ln supply of the skilled occupations, the unskilled occupations, and ln GDP per worker. To ensure that the skilled and unskilled occupations for each country are at least somewhat representative, we exclude the bottom $20 \%$ of country-periods with smallest number of wage reports by skill group, which means that there are at least 6 occupations by skill group for each country (on average, 12 skilled and 26 unskilled occupations). With this restriction, the average change in panel A is calculated based on 118 countries, and the average selected period is 1960-1964 to 1990-1994. The estimates in panel B are based on the augmented models in columns (5)-(8) of Table 4 , and averages are scaled to a 25 year-period. Skilled-unskilled premia are based on at least 13 occupations by skill group for each country (on average, 36 skilled and 50 unskilled occupations), and the average selected period is 1985-1989 to 2000-2004. The average change is calculated based on 37 countries. 


\section{Appendices}

\section{A The Importance of Occupations in Wage Determina- tion}

In this Appendix, we address three questions:

1. What is the explanatory power of occupations for wages across countries?

2. Has the explanatory power of occupations changed over time in recent decades?

3. Is the explanatory power of occupations higher in countries with lower levels of formal education?

In order to investigate these questions, we use internationally comparable cross-country microdata on employment and wages for 47 countries from the Luxembourg Income Study Database (LIS) over the period 1980-2018 41 We select all individuals aged 25-64 who are regularly employed, excluding those employed by the military or with 'indistinguishable' occupations (in main job) ${ }^{42}$ Education is measured by the highest level of education completed, either in harmonized format (9 categories) or in country-specific format (between 3 and 83 categories) ${ }^{43}$ The harmonized occupation (in main job) is based on the 9 major groups of ISCO classification (apart from armed forces occupations) ${ }^{44}$ Countries often reported also occupations according to their country-specific occupational classification, with between 5 and 1197 occupations. For wages we also used two measures, namely (log of)

\footnotetext{
${ }^{41}$ The LIS includes also data for the period 1967-1979 but they form only $3.5 \%$ of the available country-year pairs.

${ }^{42}$ See https://www.lisdatacenter.org/wp-content/uploads/files/data-lis_codebook.pdf.

${ }^{43}$ The 9 harmonized categories are less than primary, primary, lower secondary, upper secondary, postsecondary non-tertiary, short-cycle tertiary, bachelor or equivalent, master or equivalent, doctorate or equivalent.

${ }^{44}$ Managers, professionals, technicians and associate professionals, clerical support workers, services and sales workers, skilled agricultural/forestry/fishery workers, craft and related trades workers, plant and machine operators and assemblers, and elementary occupations.
} 
hourly wages as well as (log of) wage income. 45 For hourly wages, we took the gross pay, if available, otherwise the net pay. ${ }^{46}$

\section{What is the Explanatory Power of Occupations for Wages?}

In Figure A.1, we report the (adjusted) R-squared values of regressions of wages on the harmonized education (9 categories) respectively occupation (ISCO, 9 categories) dummies by country-year, weighted with sampling weights to make them representative of the population of regularly employed between 25-64 years old in the country (except armed forces) and averaged by country. The R-squared values are reported after partialing-out for age, age-squared, gender and the interactions of gender with age (squared). The R-squared for the regression(s) of hourly wages are reported, unless hourly wages were not available for any year in a given country and the results for the regression(s) of wage income are used instead (in 10 of the 42 countries which reported both education and occupation in harmonized format). The Figure shows that the 9 category ISCO occupations explain more or less the same amount of wage variation as the 9 education dummies, but typically more (in 31 countries more versus in 11 countries less).

\footnotetext{
${ }^{45}$ Wage income: monetary payments received from regular and irregular dependent employment. This includes cash wage and salary income (gross of social security contributions and income taxes) and monetary supplements to the basic wage, such as overtime pay, employer bonuses, 13th month bonus, profit-share, tips.

${ }^{46}$ Overtime payments, bonuses and gratuities, family allowances and other social security payments made by employers, as well as ex gratia payments in kind supplementary to normal wage rates, are all excluded from the calculation of the hourly wage.
} 


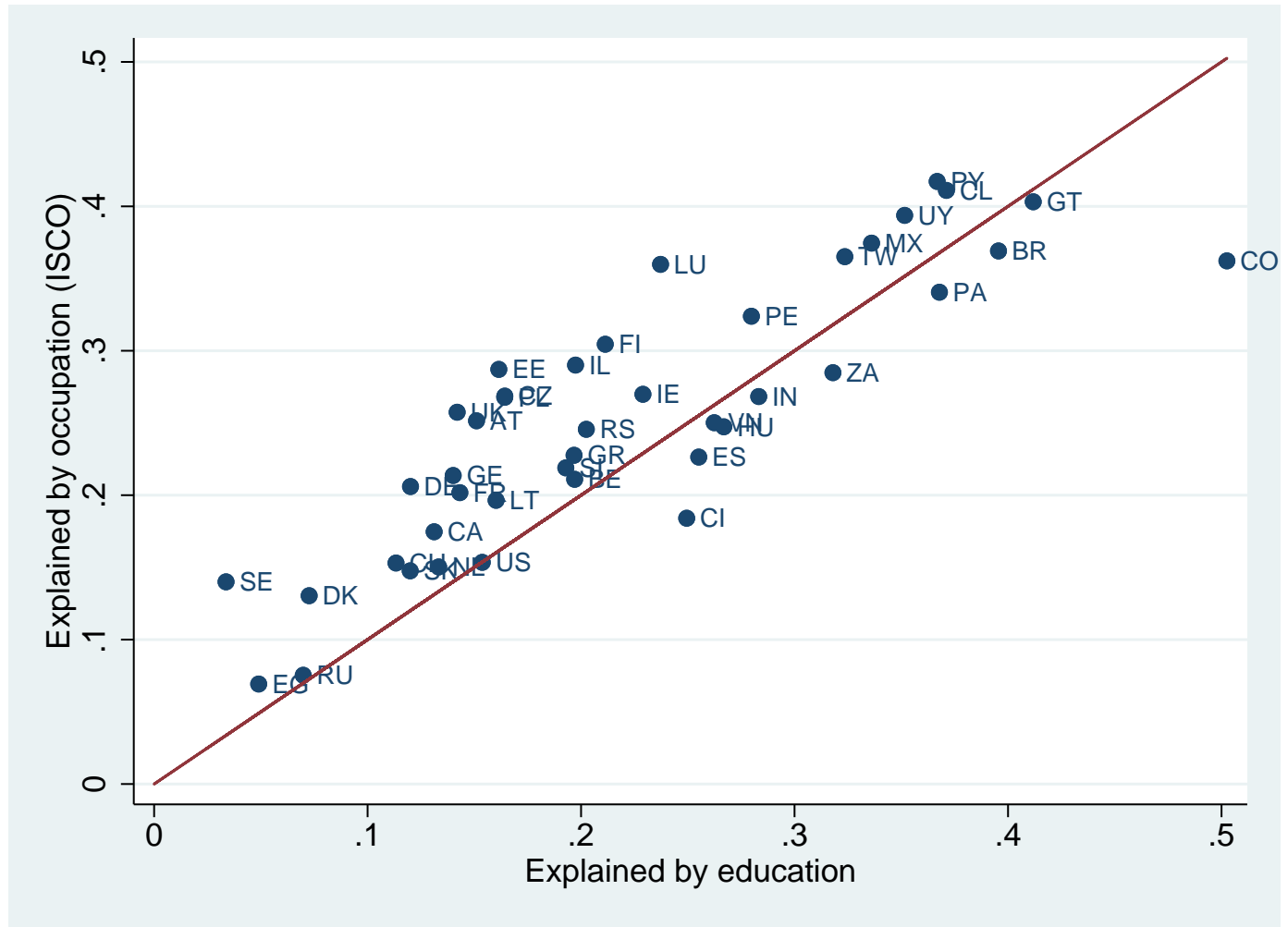

Figure A.1: Share of Wage Variation Explained by 9 Harmonised Education versus 9 Harmonised Occupation Categories, by Country.

Source: Luxembourg Income Study Database.

If we use all available (country-specific) education and occupation categories, the occupational dummies explain almost uniformly more than the education dummies (i.e. they are almost always above the 45-degree line, see Figure A.2. This is a consequence of the fact that the reported categories for education are far less granular than those for occupations (on average countries report 16.6 educational categories against 138.9 occupations). 


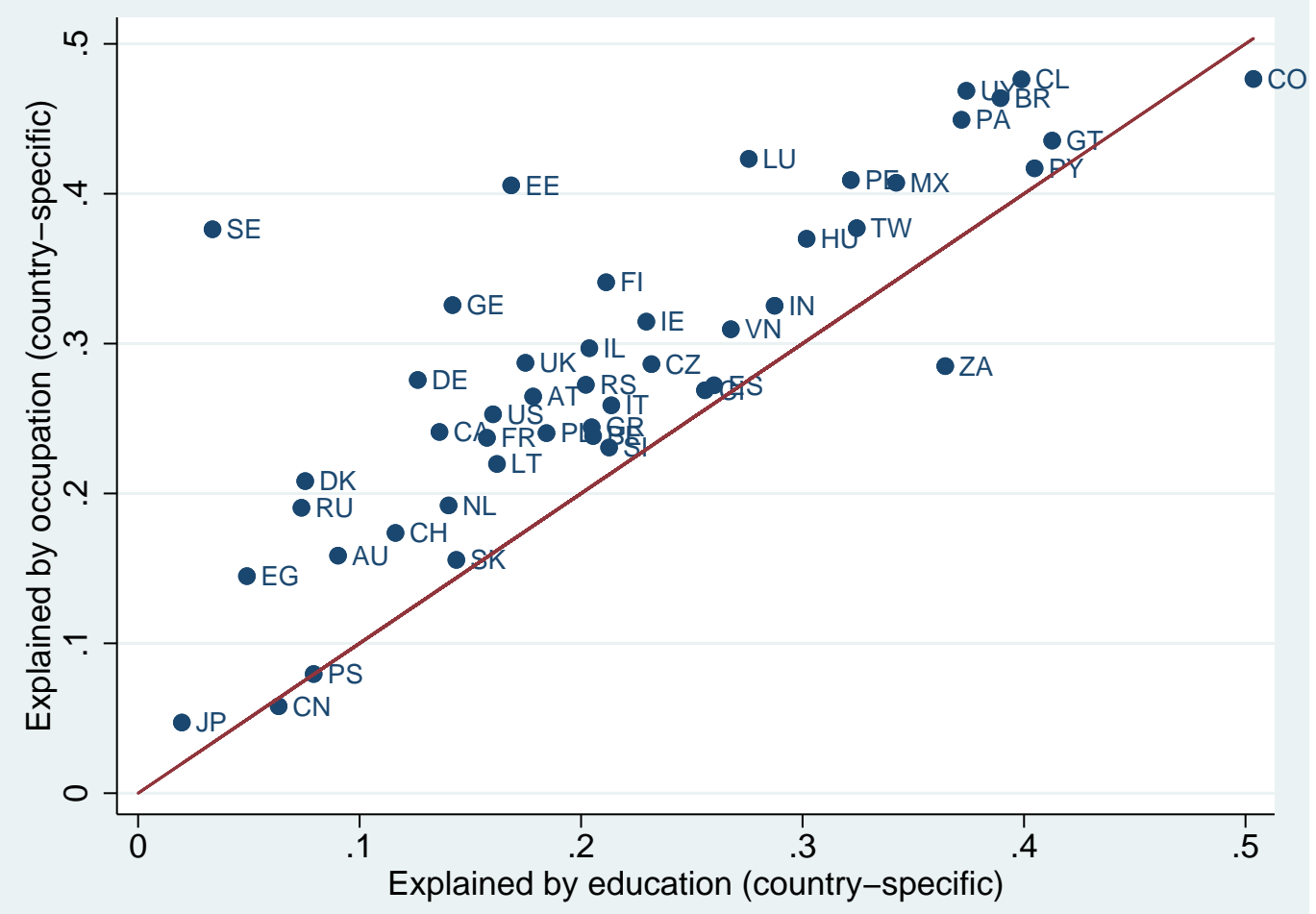

Figure A.2: Share of Wage Variation Explained by all available Education versus all available Occupation Categories, by Country.

Source: Luxembourg Income Study Database.

\section{Has the Explanatory Power of Occupations Changed over Time in Recent Decades?}

Do we also find that occupations are of growing importance for explaining wages as found for the USA by Acemoglu and Autor (2011)? Because we have calculated the contribution of education and occupation by country and year, we regress the corresponding R-squared values on decade dummies and a dummy for whether wage income (instead of hourly wage) is used. We use the R-squared from the regressions with the harmonized education and occupation dummies, as the broader country-specific measures vary over time. Because also country fixed effects are included, we identify within-country time trends in the explanatory power of education and occupation. Column (1) in Table A.1 shows that the explanatory power of education rises with $0.025-0.039$ since the 2000 s in our sample of (forty-two) coun- 
tries. Consistent with the finding for the USA, column (2) shows that the recent rise in explanatory power of occupations was more rapid at $0.040-0.055$ since the 2000 s. If we calculate the increase in the R-squared of a wage regression on education after including occupation dummies, we also note that the marginal contribution of occupations in addition to education is increasing over time (column (3)). Hence, we can conclude that the observed finding on the growing importance of occupations in wage determination is not only a US phenomenon but also holds in the broad LIS sample of 42 countries.

Table A.1: Explanatory power of education vs. occupations in wage regressions: change over time

Dependent variable: R2 of wage regression

\begin{tabular}{lccc}
\hline \hline & $\begin{array}{c}(1) \\
\text { educ }\end{array}$ & $\begin{array}{c}(2) \\
\text { occ }\end{array}$ & $\begin{array}{c}(3) \\
\text { occ }\left.\right|_{\text {educ }}\end{array}$ \\
\hline $1990 \mathrm{~s}$ & -0.007 & 0.001 & 0.007 \\
& $(0.012)$ & $(0.016)$ & $(0.009)$ \\
$2000 \mathrm{~s}$ & $0.039^{*}$ & $0.055^{* *}$ & $0.017^{+}$ \\
& $(0.015)$ & $(0.019)$ & $(0.010)$ \\
$2010 \mathrm{~s}$ & $0.025^{+}$ & $0.040^{*}$ & $0.016^{+}$ \\
& $(0.013)$ & $(0.017)$ & $(0.009)$ \\
Wage income & -0.020 & -0.013 & 0.001 \\
& $(0.015)$ & $(0.018)$ & $(0.008)$ \\
\hline Country FE & $\checkmark$ & $\checkmark$ & $\checkmark$ \\
Countries & 42 & 42 & 42 \\
R2 & 0.878 & 0.812 & 0.632 \\
Observations & 214 & 219 & 213 \\
\hline \hline
\end{tabular}

Source: Luxembourg Income Study Database. Robust standard errors in parentheses. ${ }^{+} p<0.1,{ }^{*} p<0.05,{ }^{* *} p<0.01$. "Wage income" is a dummy that equals 1 if the R2 comes from a regression of wage income instead of the hourly wage.

\section{Is the Explanatory Power of Occupations Higher in Countries with Lower Levels of Formal Education?}

Do we observe a relatively greater explanatory power of occupations for earnings in developing countries where formal educational attainments are relatively low and on-the-job learning presumably a relatively more important component of skill formation? Table A.2 shows that 
there is a negative correlation between the (marginal) explanatory power of occupations and the average years of schooling a country, but only for the 1980-90s (columns (1)-(3)). Because not the same countries are reported for both periods and at the same frequency, as a robustness check we rerun the same regression for all countries that are reported in both periods taking the earliest and latest observation for each country to maximize the time span. Also in this case we find that occupations have a relatively stronger explanatory power beyond education in countries with lower levels of education, as expected if occupations capture returns to informal learning and innate skills. The fact that we do not find this as clearly for the later period (the coefficient is still negative but smaller and insignificant) might be due to high income countries increasingly being affected by polarization and offshoring in recent decades, making occupations also more important in high education countries.

Table A.2: Explanatory power of education vs. occupations in wage regressions: change over time

Dependent variable: $\mathrm{R} 2$ of wage regression

\begin{tabular}{|c|c|c|c|c|c|}
\hline & $\begin{array}{c}(1) \\
\text { occ| }\left.\right|_{e d u c}\end{array}$ & $\begin{array}{c}(2) \\
\text { occ }\left.\right|_{e d u c}\end{array}$ & $\begin{array}{c}(3) \\
\text { occ }\left.\right|_{e d u c}\end{array}$ & $\begin{array}{c}(4) \\
\text { occ| }\left.\right|_{e d u c}\end{array}$ & $\begin{array}{c}(5) \\
\text { occ }\left.\right|_{\text {educ }}\end{array}$ \\
\hline & All years & $1980 \mathrm{~s}-90 \mathrm{~s}$ & $2000 \mathrm{~s}-2010 \mathrm{~s}$ & $1980 \mathrm{~s}-90 \mathrm{~s}$ & $2000 s-2010 s$ \\
\hline Years of schooling & $\begin{array}{c}-0.000 \\
(0.002)\end{array}$ & $\begin{array}{c}-0.006^{* *} \\
(0.002)\end{array}$ & $\begin{array}{c}0.002 \\
(0.002)\end{array}$ & $\begin{array}{c}-0.008^{* *} \\
(0.002)\end{array}$ & $\begin{array}{c}-0.004 \\
(0.006)\end{array}$ \\
\hline Wage income & $\begin{array}{c}0.001 \\
(0.008)\end{array}$ & $\begin{array}{l}-0.003 \\
(0.010)\end{array}$ & $\begin{array}{l}-0.001 \\
(0.008)\end{array}$ & $\begin{array}{c}0.009 \\
(0.016)\end{array}$ & $\begin{array}{c}0.008 \\
(0.018)\end{array}$ \\
\hline Constant & $\begin{array}{l}0.080^{* *} \\
(0.019)\end{array}$ & $\begin{array}{l}0.135^{* *} \\
(0.020)\end{array}$ & $\begin{array}{c}0.055^{*} \\
(0.021)\end{array}$ & $\begin{array}{l}0.142^{* *} \\
(0.022)\end{array}$ & $\begin{array}{l}0.137^{+} \\
(0.069)\end{array}$ \\
\hline Countries & 40 & 24 & 39 & 23 & 23 \\
\hline $\mathrm{R} 2$ & 0.169 & 0.361 & 0.147 & 0.181 & 0.040 \\
\hline Observations & 209 & 75 & 134 & 23 & 23 \\
\hline
\end{tabular}

Source: Luxembourg Income Study Database. Standard errors are clustered by country (columns (1)-(3)), or robust (columns (4)-(5)), in parentheses. ${ }^{+} p<0.1,{ }^{*} p<0.05,{ }^{* *} p<0.01$. "Wage income" is a dummy that equals 1 if the $\mathrm{R} 2$ comes from a regression of wage income instead of the hourly wage. 


\section{B Additional Results}

\section{Studying Skill Premia using the OWW Database}

Our distinction between unskilled occupations (requiring at most primary education), medium skilled occupations (requiring some degree of secondary education), and skilled occupations (requiring post-secondary education) is taken from ILO (2021). However, the second skill level of the ILO (i.e., the "secondary education"/our "medium skilled" category) contains a broad range of occupations, ranging from some that arguably require only basic literacy and numeracy skills obtained at the latest during the first stage of secondary education (for instance occupation 26, "loom fixer, tuner"), to occupations arguably requiring more advanced skills from the second stage of secondary education or specialized vocational education (for instance occupation 131, "bank teller"). Hence, we further distinguish between lower medium skilled occupations, likely to require only basic secondary education, and upper medium skilled occupations, likely to require completed secondary education, based on the typical position of the occupations in countries' occupational wage rankings.

We estimate this position using the ranking of occupation fixed effects in a regression of $\ln$ wages that includes country, occupation and period fixed effects. In our preferred classification, among the occupations at the second skill level of the ILO, we classify the bottom two-thirds of the occupations in this ranking as "lower medium skilled" and the top third as "upper medium skilled", as this is a transparent criterion that yields a classification that is similar to the classification we got from a subjective estimation of skill requirements from the job descriptions. See Appendix $\mathrm{D}$ for a full list of the occupations which includes their skill group.

We have probed the robustness of our analyses with respect to two alternative skill requirement classifications: a purely "theoretical" one, for which the differentiation between lower and upper medium skilled occupations is solely based on the inspection of job titles, and a purely "empirical" one that is solely based on the ranking of occupation fixed effects 
also for occupations classified as "unskilled" or "highly skilled" by the ILO. Compared to our benchmark skillgroup classification, the theoretical skill requirement classification for instance reclassifies "miners" from upper to lower medium skilled, and "hand compositors", "machine fitter-assemblers" and "mixing and blending machine operators" from lower to upper medium skilled. The empirical classification classifies the same number of occupations to the four skill groups as our preferred one, but picks them exclusively on the basis of the ranking of occupation fixed effects. Results using both alternative classifications tend to be similar to our benchmark results (available upon request). 
2000s vs. 1950 s: $R h o=0.76$, pval $=0.00$

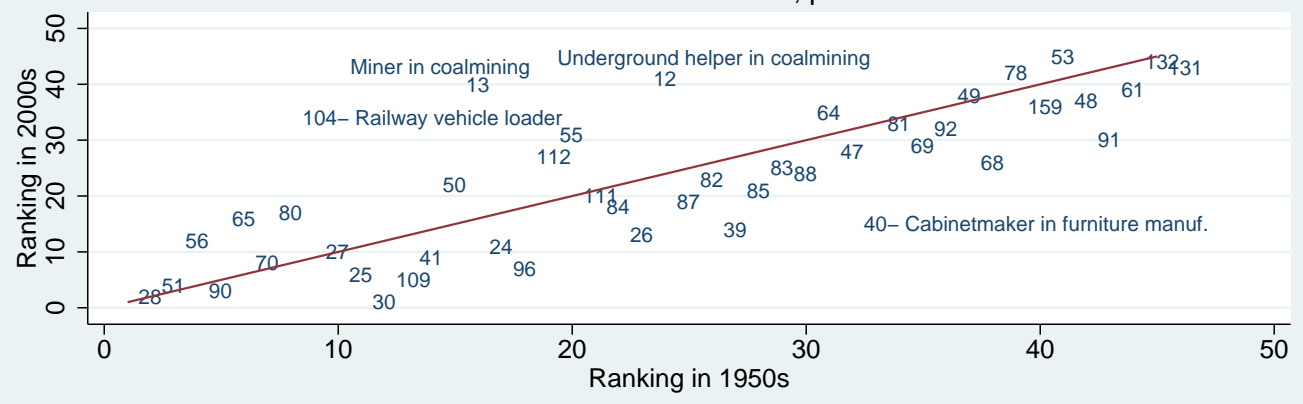

2000s vs. 1980 s: $R h o=0.94$, pval $=0.00$

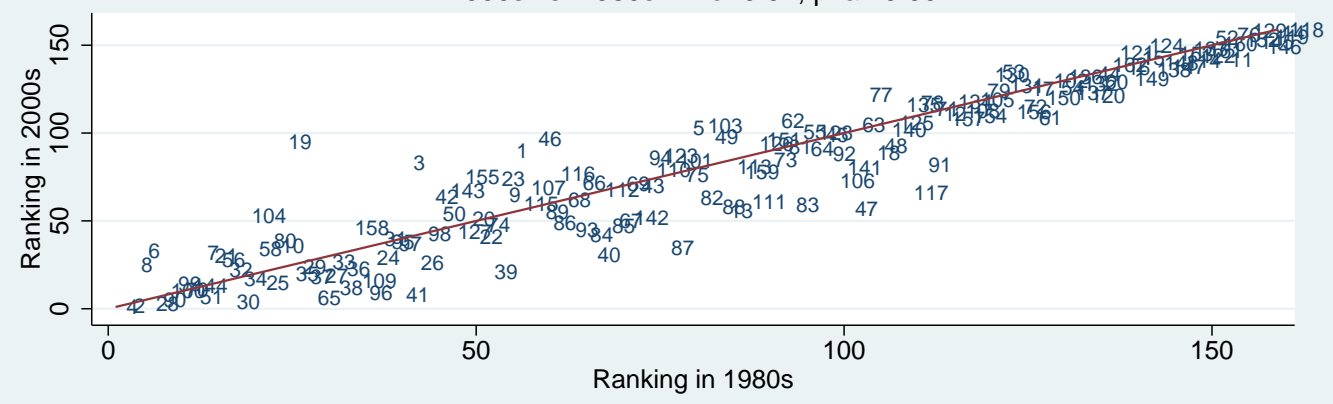

Figure B.1: Correlation between Wage Rankings over Time

The ranks are based on the occupation fixed effects from a regression of log wages on country and occupation fixed effects. A higher rank corresponds to higher typical relative wages in the occupation. The labels are occupation codes, see Appendix D for the corresponding occupation and industry titles. We use the balanced samples with log-linear inter-and extrapolations of gaps in wage series of up to one decade for these analyses (see note of Figure B.2 for a description). Hence, the sample composition in term of countries and occupations is the same in both decades that are being compared. The top panel includes the 45 occupations available over the full period from 1953 to 2008. In the bottom panel, the comparison is made for the 159 occupations available from 1983 onwards. The top Figure shows that even over a period of six decades, there is a relatively clear sense of which occupations are skilled and which are not. However, there are some exceptions: Coalmining occupations were only medium skilled in the 1950s, but near the top of the wage distribution in the 2000s- arguably, because mining has become much more capital intensive, pushing up relative wages of (the remaining) coalminers. By contrast, cabinetmakers in furniture manufacturing used to be much more highly paid in the 1950 . See Kunst $(2019)$ for an analysis of the decline of the relative demand for craftsmen in manufacturing. 


\section{The Evolution of Occupational Skill Premia}

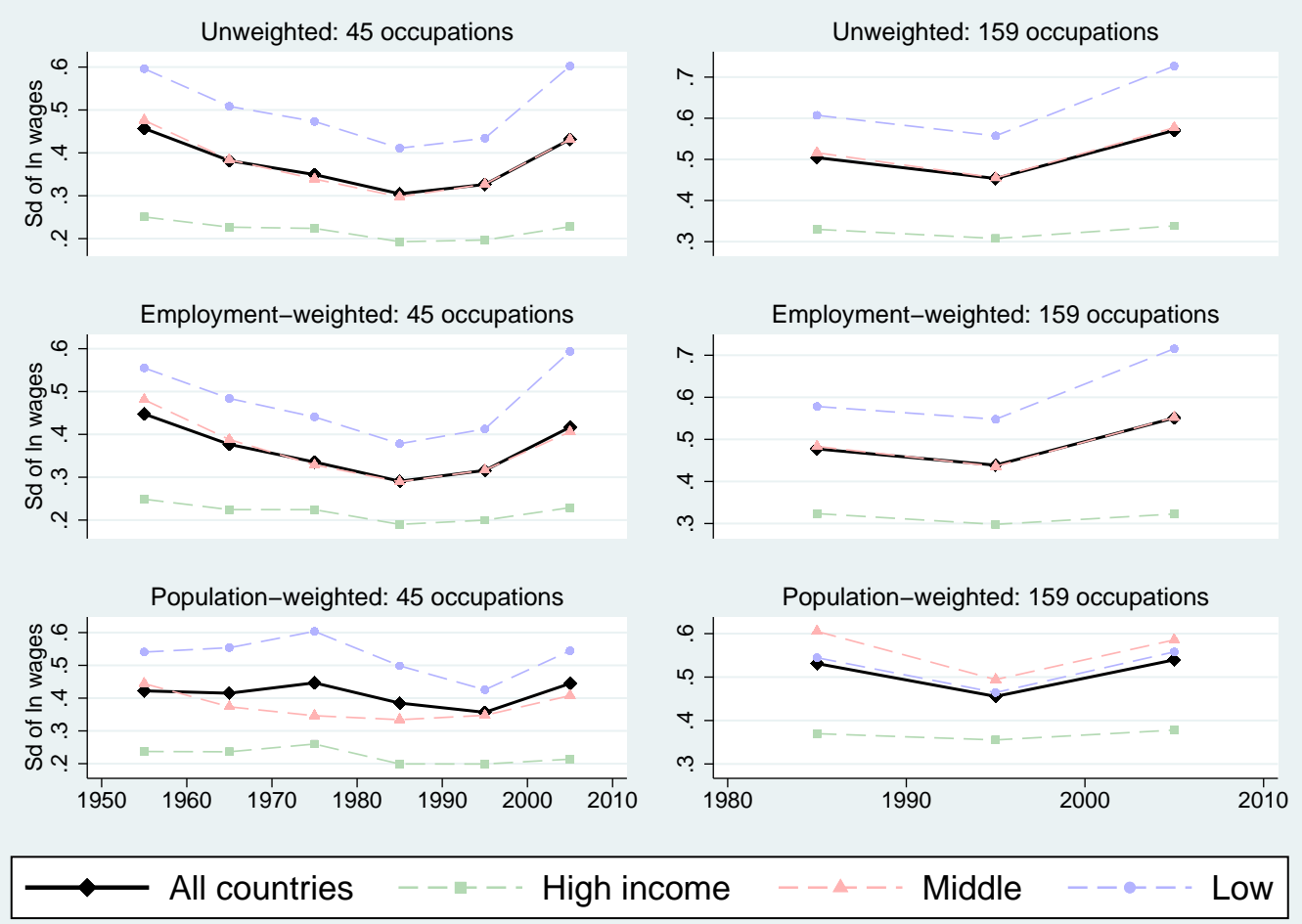

Figure B.2: Evolution of Occupational Skill Premia in Balanced Samples and with Employment- or Population Weighting

The difference to Figure 1 is that the averages for all periods are calculated for the same 91 countries in the left panel and 114 countries in the right panel, and for the same occupations in all decades. To create this balanced sample, we (i) take decade averages of all available wage reports from a country, and (ii) fill gaps of up to one consecutive decade in a country-occupation series (including endpoints) by means of linear inter- or extrapolation of log wages. We discard all country-occupation wage series that cannot be completed in this way. For the extended sample available from the 1980s, we require that data are available for at least two out of the three decades. $15 \%$ of wages have been estimated in this way in the sample of 45 occupations, and $22 \%$ in the extended sample. In the middle panel, we calculate emploment-weighted country-level standard deviations. We calculate the weight of each occupation by (i) counting the wage reports from a country-period available in each 1-digit occupation-industry cell, and (ii) dividing the employment share estimate for the respective occupation-industry cell (obtained from I2D2, cf. Section C by the number of available wage reports. In the bottom panel, we weight countries by their estimated population when calculating the averages across countries or income groups. Population data is taken from the Penn World Tables, and missing population data for some decades is filled with (i) data from the World Development Indicators if available, and (ii) the data for the nearest decade with non-missing data otherwise. The 91 countries in the left panel cover between 55 and 59 percent of the world population (and include India, but not China), and the 114 countries in the right panel cover between 85 and 86 percent of the world population (and include both India and China). 

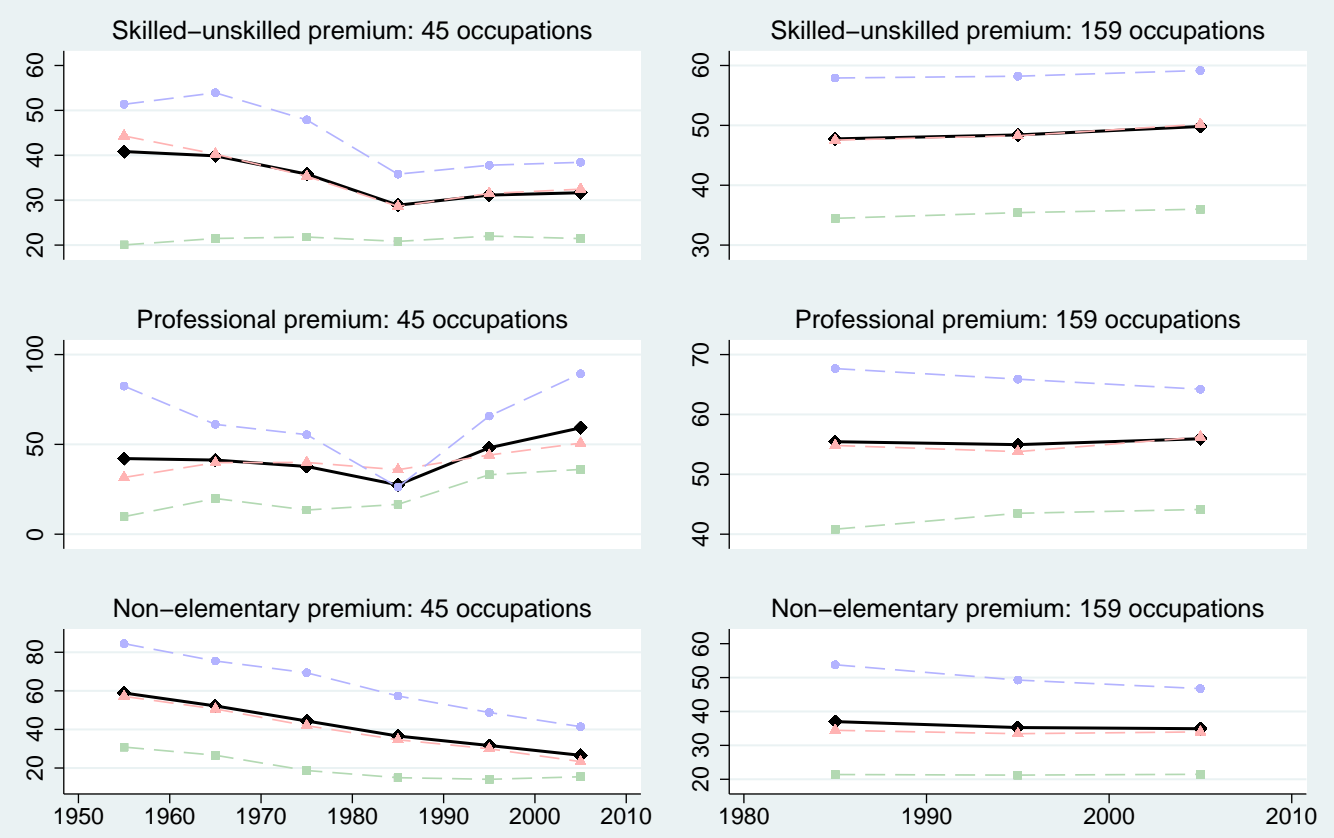

All countries - - - High income

Middle

Low

\section{Figure B.3: Evolution of Skilled-unskilled Premia in Balanced Samples}

The difference to Figure B.2 is that each panel plots the evolution of the average wage premium of a "skilled" relative to an "unskilled" occupation group, in log points: In the top panel, we classify upper medium and high skilled occupations as "skilled". In the middle panel, we only consider high skilled occupations in major groups 1-3 as "skilled". In the bottom panel, we consider all high and medium skilled occupations as "skilled", so that the reference group consists only of the elementary occupations in major group 9. 
Table B.1: Evidence on the Evolution of Occupational Skill Premia after 2008 from ILOSTAT and UBS

\begin{tabular}{llllll}
\hline \hline Source & & Countries & Decrease (\%) & Average early & Average late \\
\hline ILOSTAT & All & 75 & 62.7 & 60 & 59.4 \\
ILOSTAT & -high income & 19 & 57.9 & 64.7 & 61.1 \\
ILOSTAT & -middle income & 41 & 65.9 & 64.8 & 63.8 \\
ILOSTAT & -low income & 15 & 60 & 40.8 & 45.1 \\
UBS & All & 59 & 54.2 & 53.4 & 49.9 \\
UBS & -high income & 26 & 57.7 & 49.3 & 43.3 \\
UBS & -middle income & 28 & 57.1 & 53.3 & 49.1 \\
UBS & -low income & 5 & 20 & 75.4 & 88.8 \\
\hline \hline
\end{tabular}

The Table summarizes evidence on the evolution of occupational skill premia from ILOSTAT and the UBS prices and earnings survey between the first and the last available year between 2009 and 2018 for each country. ILOSTAT collects monthly earnings at the level of the 9 ISCO major groups. We calculate a skill premium that is similar to our OWW "skilled-unskilled premium" by assigning the four highest-wage major groups (managers, professionals, associate professionals and clerks to the "skilled" category, and the other five major groups to the "unskilled" category.

Monthly earnings for all 9 major groups are available for all countries, and the average time period is 2011 to 2016. The second data source is the "Prices and Earnings Survey" by UBS, which collects earnings for selected occupations from capitals around the world. To calculate "skilled-unskilled" premia from the UBS data, we use the approximate matching between OWW and UBS occupations done by Hammar and Waldenström (2019). For UBS, the number of occupations ranges from 10-14 with an average of 11 occupations, and the time period is 2009-2018 for all but one country (for which 2012 is the last year). 


\section{Additional Estimation Results}

Table B.2: Regression Estimates of the Determinants of Occupational Wages: Trade by Occupation Skill Group and Income Group

Dependent variable: ln real wage

\begin{tabular}{lcccc}
\hline \hline & $(1)$ & $(2)$ & $(3)$ & $(4)$ \\
& low & l. medium & u. medium & high \\
\hline ln supply & -0.21 & $-0.17^{+}$ & -0.08 & $-0.19^{*}$ \\
& $(0.19)$ & $(0.09)$ & $(0.10)$ & $(0.08)$ \\
ln GDP/worker & $0.92^{* *}$ & $0.90^{* *}$ & $0.73^{* *}$ & $0.79^{* *}$ \\
& $(0.16)$ & $(0.14)$ & $(0.13)$ & $(0.13)$ \\
trade/GDP & -0.02 & -0.08 & 0.06 & -0.01 \\
& $(0.12)$ & $(0.12)$ & $(0.12)$ & $(0.11)$ \\
x low+middle income & -0.28 & -0.25 & -0.14 & 0.32 \\
& $(0.28)$ & $(0.25)$ & $(0.23)$ & $(0.22)$ \\
union density & $0.37^{+}$ & $0.40^{+}$ & 0.23 & 0.22 \\
& $(0.19)$ & $(0.20)$ & $(0.19)$ & $(0.21)$ \\
\hline Country-occup. FE & $\checkmark$ & $\checkmark$ & $\checkmark$ & $\checkmark$ \\
Period FE & $\checkmark$ & $\checkmark$ & $\checkmark$ & $\checkmark$ \\
Countries & 47 & 48 & 48 & 44 \\
Occupations & 16 & 74 & 37 & 35 \\
Industries & 14 & 27 & 18 & 17 \\
Intervals & 5 year & 5 year & 5 year & 5 year \\
R2 (within) & 0.63 & 0.56 & 0.51 & 0.42 \\
Observations & 2187 & 9866 & 4429 & 3305 \\
\hline \hline
\end{tabular}

Standard errors in parentheses, clustered at the country level. ${ }^{+} p<0.1,{ }^{*} p<0.05,{ }^{* *} p<0.01$. The difference in the point estimates between the lowest and the highest skill group for the interaction terms of trade to GDP with a "low or middle income"-dummy is statistically significant $(\mathrm{p}=0.02)$. Note that this is also the case when omitting union density from the specification, which increases the sample size to 117 countries ( $\mathrm{p}=0.01$, results available upon request). 


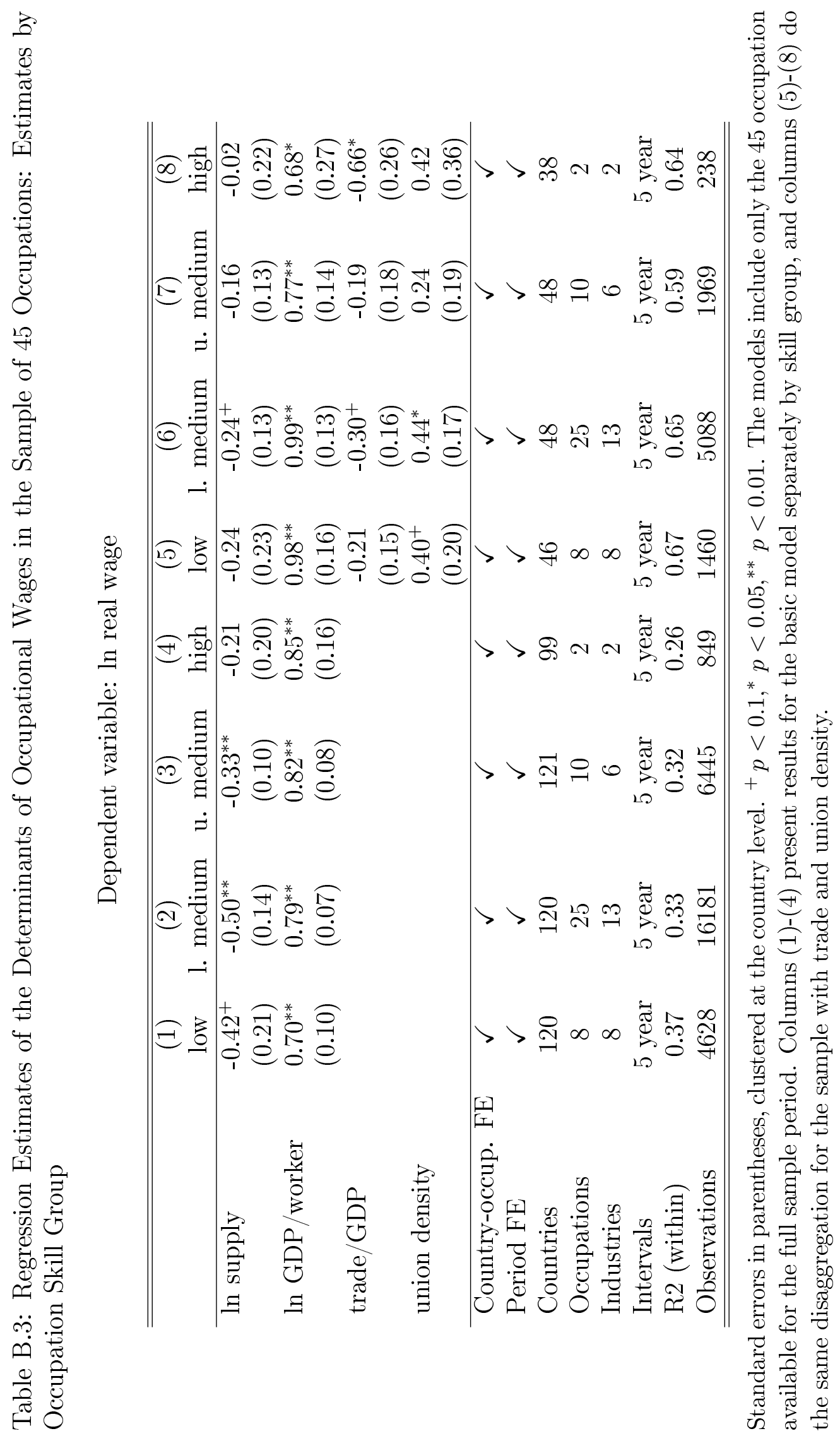




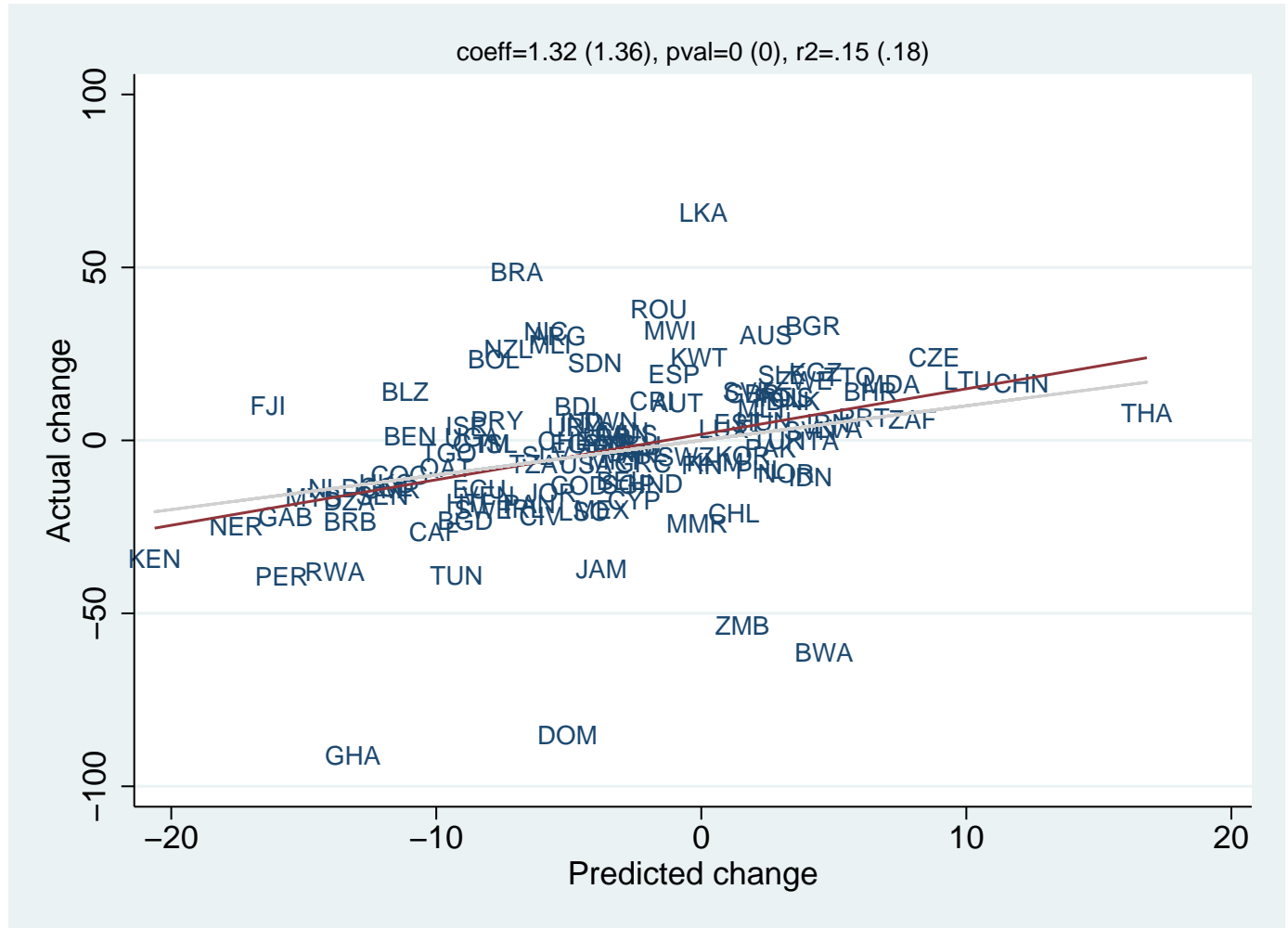

Figure B.4: Comparing the Actual Changes of the Skilled-Unskilled Premium over the Full Sample Period to the Changes Predicted by the Basic Model

The Figure plots the simulation results that are also summarized in panel A of Table 5 . Hence, the predicted skill premium changes take into account changes in ln supply, period $\mathrm{x}$ skill group dummies, and GDP per worker. The title presents the results from a regression of actual on predicted wage premium changes. In brackets are the results from the same regression in which we give more weight to more precisely estimated wage premium changes, by weighting the wage premium changes from each country with the geometric mean of the square root of the number of skilled and unskilled occupations based on which it has been calculated. 


\section{Data Appendix}

\section{Data Sources \& Sample Information}

Next to the extended OWW database, whose construction is presented in detail in Freeman and Oostendorp (2020), we use data from the following sources:

- Penn World Table 9.0 by Feenstra et al. (2015): real GDP per worker, contructed by dividing "rgdpna" (GDP in constant national prices in 2011 USD) by "emp" (number of persons engaged). GDP deflator for conversion of current USD wages to real wages in constant national prices in 2011 USD, constructed by dividing GDP in current USD ("v_gdp"/"xr2") by GDP in constant national prices ("rgdpna").

- Schooling dataset by Barro and Lee (2013), version 2.2: average educational attainments for the total population aged 15 and above. Data are available every 5 years, starting in 1950. We take the average of two neighboring reports to obtain our estimate for the corresponding 5 year-period.

- International Income Distribution database (I2D2): data retrieved from the World Bank in March 2019. See Section C for more details, and Montenegro and Hirn (2009) for a description of the database.

- World Development Indicators by World Bank (2019): data on merchandise trade/GDP, available from 1960 onwards. Retrieved in March 2019.

- Data Base on Institutional Characteristics of Trade Unions, Wage Setting, State Intervention and Social Pacts, 1960-2017 (ICTWSS) by Visser (2019), version 6.0: "ud"union density rate, net union membership as a proportion of wage earners in employment.

- Luxembourg Income Study Database, see Appendix A. 
Table C.1 presents descriptive statistics on the variables in the regression samples in Section 4. While supply, GDP per worker, trade to GDP and union density are matched to multiple occupations in these regressions, the summary statistics are only calculated across the distinct country-period observations (or country-major group-period observations in the case of supply) in the samples in columns (2) (for supply and GDP/worker) or (5) (for trade/GDP and union density) of Table 3 .

Table C.1: Summary Statistics of Variables in the Regression Samples

\begin{tabular}{lllllll}
\hline \hline & Observations & Countries & Mean & Standard deviation & Minimum & Maximum \\
\hline ln real wage & 51113 & 122 & 1.58 & .93 & -2.3 & 5.27 \\
ln supply & 5784 & 122 & -2.38 & .95 & -9.31 & -.13 \\
ln GDP/worker & 871 & 122 & 9.82 & 1.07 & 6.7 & 12.99 \\
trade/GDP & 277 & 48 & .59 & .54 & .07 & 3.35 \\
union density & 277 & 48 & .39 & .21 & .05 & .93 \\
\hline \hline
\end{tabular}




\section{Estimating the Occupational Employment Distribution by Education Level from I2D2}

I2D2 is a collection of harmonized nationally representative surveys maintained by the World Bank, and introduced in Montenegro and Hirn (2009). It has been expanded considerably since its inception, and we use the surveys included in I2D2 as of March 2019. I2D2 is not yet publicly available. We use the I2D2 surveys to estimate the distribution of occupational employment by education level as follows:

1. we restrict each sample to wage-employed men and women aged 15-64. We exclude workers classified as self-employed, non-wage employed or employer in order to match the OWW population.

2. we keep only surveys with harmonized information on the education level (no schooling, primary-, secondary- or post-secondary schooling) and the occupation (one of the 9 civilian major groups of ISCO-88). We also exclude about $9 \%$ of surveys that do not contain observations for all 9 major groups, as the discussion in Montenegro and Hirn (2009) raises the questions whether the standardization of national classifications has been fully successful for such surveys. The top row of Table C.2 shows that this leaves us with a total of 881 surveys from 142 countries. The survey years range from 1960 to 2016, but only 3 percent of the surveys are from before 1990, and 16 percent from before 2000. The average survey year is 2005 .

3. we calculate the occupational employment distribution for each survey and each of the four education levels, using the survey weights. We only estimate the employment distribution across the nine occupations for an education level if a survey includes at least 10 observation with the respective education level. This yields a maximum of 36 coefficients per survey if the occupational employment distribution can be estimated for all education levels (4 education levels x 9 occupations). 
4. we calculate the average employment distribution for each country-education level if distributions from several surveys are available for a country, using the square root of the number of survey observations with the respective education level as a weight.

5. this procedure leaves us with a country-specific occupational employment distribution for all four education levels for 75 of the 122 countries in the basic model in column (1) of Table 3. For the remaining 47 countries, we impute employment distributions with the average distribution of one of nine country-income groups: high income countries, and middle and low income countries by region as presented in Table C.2. The selection of country-income groups was informed by an ANOVA of the coefficients from step 3, which revealed significant heterogeneity in employment distributions across these country-income groups. We did not distinguish between high income-countries from different regions as very few of them lie outside of Western Europe and North America.

Table C.2: Summary of I2D2 Surveys

\begin{tabular}{llllllll}
\hline \hline & Countries & Surveys & Avg. year & \multicolumn{4}{c}{ With employment distribution for...schooling } \\
& & & & no & primary & secondary & post-secondary \\
\hline All & 142 & 881 & 2005 & 656 & 812 & 872 & 856 \\
High income & 20 & 135 & 2007 & 42 & 105 & 135 & 135 \\
Middle inc. Africa & 17 & 78 & 2005 & 74 & 77 & 77 & 72 \\
Middle inc. ECA & 25 & 146 & 2006 & 40 & 111 & 143 & 132 \\
Middle inc. rest Asia & 16 & 126 & 2003 & 119 & 126 & 123 & 123 \\
Middle inc. LACA & 20 & 186 & 2002 & 180 & 185 & 186 & 186 \\
Low inc. Africa & 24 & 79 & 2007 & 74 & 77 & 77 & 77 \\
Low inc. ECA & 2 & 4 & 2007 & 2 & 4 & 4 & 4 \\
Low inc. rest Asia & 15 & 111 & 2005 & 109 & 111 & 111 & 111 \\
Low inc. LACA & 3 & 16 & 2003 & 16 & 16 & 16 & 16 \\
\hline \hline
\end{tabular}

"ECA" stands for Europe and Central Asia, "LACA" for Latin America. The last four columns indicate the number of surveys for which the occupational employment distribution for the respective educational attainment level could be estimated.

We have assessed the sensitivity of the supply elasticities in column (1) of Table 3 to the following alternative ways of constructing the employment distributions:

- using only surveys from up to or after the year 2000 
- excluding surveys in which the share of employees working in skilled occupations does not increase in the education level (up to post-secondary education for managers and professionals, and up to secondary education for clerks and associate professionals, allowing for a 5 percentage point tolerance)

- calculating the income-region group average employment distributions only based on surveys for which employment distributions for all education levels could be estimated

- imputing missing country-specific employment distributions with coarser income group instead of income-region group averages

- using income-region or income group average employment distributions for all countries (even when country-specific employment distribuitions could be estimated)

- only keeping the 75 countries in the sample for which I2D2 allows for the construction of country-specific employment distributions

Supply elasiticity point estimates always remain negative and significant. They range between -0.18 and -0.46 for the basic model (compared to the benchmark estimate of -0.32), and between -0.14 and -0.30 for the full model with trade/GDP and union density (compared to the benchmark estimate of -0.17).

\section{OWW Occupations and I2D2 Surveys}

This section addresses two questions:

1. what do the I2D2 surveys tell us about the share of wage employment covered by the occupations in OWW?

2. how much of the wage variation among the OWW occupations is across as opposed to within the nine major groups that the I2D2 surveys distinguish between? 
To answer the first question, we can make use of the fact that the I2D2 surveys allow us to calculate the share of wage employment in each of 90 industry-occupation 'cells' (9 occupations x 10 industries). The first column of Table C.3 presents the average employment shares by industry, aggregated across the 9 occupations, for 137 countries with the necessary occupation and industry variables. The second column shows the number of OWW occupations from the respective industry. We consider an industry-occupation cell to be represented in OWW if at least one of the OWW occupations can be matched to it, using the ILO correspondence between OWW occupations and the 1-digit ISIC-88 and ISCO-88 industry and occupation-classifications. The third column shows that industry-occupation cells covering a bit less than three quarters of all wage employment are represented in OWW. With the exception of agriculture, the occupation cells with representation in OWW cover more than half of the employment in all industries. The last two columns show that the 45 occupations available over the full period lack representation of two service industries and agriculture, and cover industry-occupation cells that on average constitute about one third of wage employment in the I2D2 surveys.

We have confirmed the robustness of our results in Section 5 to weighting the occupational wages by their estimated employment when calculating the skilled-unskilled premia. We do this on the basis of the employment share for each of the 90 industry-occupation cells (10 industries x 9 occupations). For countries not in I2D2, we impute employment shares with the average for the corresponding income-region country group that we also use for the imputation of employment distributions by education level. More specifically, we construct an employment weight for each country-occupation by dividing the employment share by occupation-industry cell by the number of occupational wage reports from this cell that are available for a country. However, the distribution of employment weights is very skewed (not shown), and hence weighting comes at the cost of increased measurement error by putting more weight on a few wage reports with large weights. Moreover, reports from occupations with smaller employment shares can still be indicative of the wages paid for occupations 
with similar skill requirements. Hence, our benchmark results do not weight by estimated employment. However, results are similar when weighting the occupations by estimated employment (available upon request).

Table C.3: Estimated Employment Coverage of OWW Database

\begin{tabular}{|c|c|c|c|c|c|}
\hline & \multirow[b]{2}{*}{ Empl. } & \multicolumn{2}{|c|}{ "All OWW occupations } & \multicolumn{2}{|c|}{45 OWW occupations } \\
\hline & & No. & Empl. covered & No. & Empl. covered \\
\hline Agriculture & 10.3 & 10 & 3.8 & 0 & \\
\hline Mining \& quarrying & 1.3 & 9 & 1.1 & 2 & .6 \\
\hline Manufacturing & 14.2 & 55 & 12.8 & 23 & 11.9 \\
\hline Electricity, gas, water & 2 & 5 & 1.5 & 2 & .8 \\
\hline Construction & 8.8 & 11 & 6.4 & 8 & 6.4 \\
\hline Wholesale, retail \& hotels & 13.9 & 11 & 11.8 & 4 & 8.9 \\
\hline Transport, storage \& communication & 7.6 & 28 & 6.7 & 4 & 4.4 \\
\hline Finance, insurance \& real estate & 7.5 & 9 & 4.5 & 2 & 1.5 \\
\hline Public administration & 20.5 & 8 & 13 & 0 & \\
\hline Other services & 14.1 & 16 & 10 & 0 & \\
\hline TOTAL & 100 & 162 & 71.6 & 45 & 34.5 \\
\hline
\end{tabular}

The first column shows the average share in civilian working age employment across 137 countries in I2D2 by industry. The second column contains the number of distinct OWW occupations in the respective industry. All of these occupations belong to one of nine ISCO-88 major groups. The third column contains the total share of civilian employment in major groups for which OWW contains at least one occupation from the respective industry. Columns four and five present the corresponding numbers only for the 45 occupations included in OWW over the full sample period.

The second question matters since I2D2 only allows us to construct our occupational labor supplies at the major group level (for lack of a more detailed harmonized occupation classification in the I2D2 surveys). Hence, we can only hope to explain changes in occupational wages and skill premia that play out across (as opposed to within) major groups with our occupational labor supply variable. Figure C.1 plots the typical deviation of occupational wage reports from the average wage reported by a country in the wage data for each of the major groups. It shows that there is considerable variation between major groups: major group-dummies explain 60 percent of the variation of occupation fixed effects among all occupations (which increases to 68 percent when excluding four highly paid occupations in the airline industry), and 69 percent of the variation among the 45 occupations available 
throughout the full period. Hence, while constructing our supply measure at the major group level introduces measurement error, we expect it to be relevant to explaining wage changes in OWW.
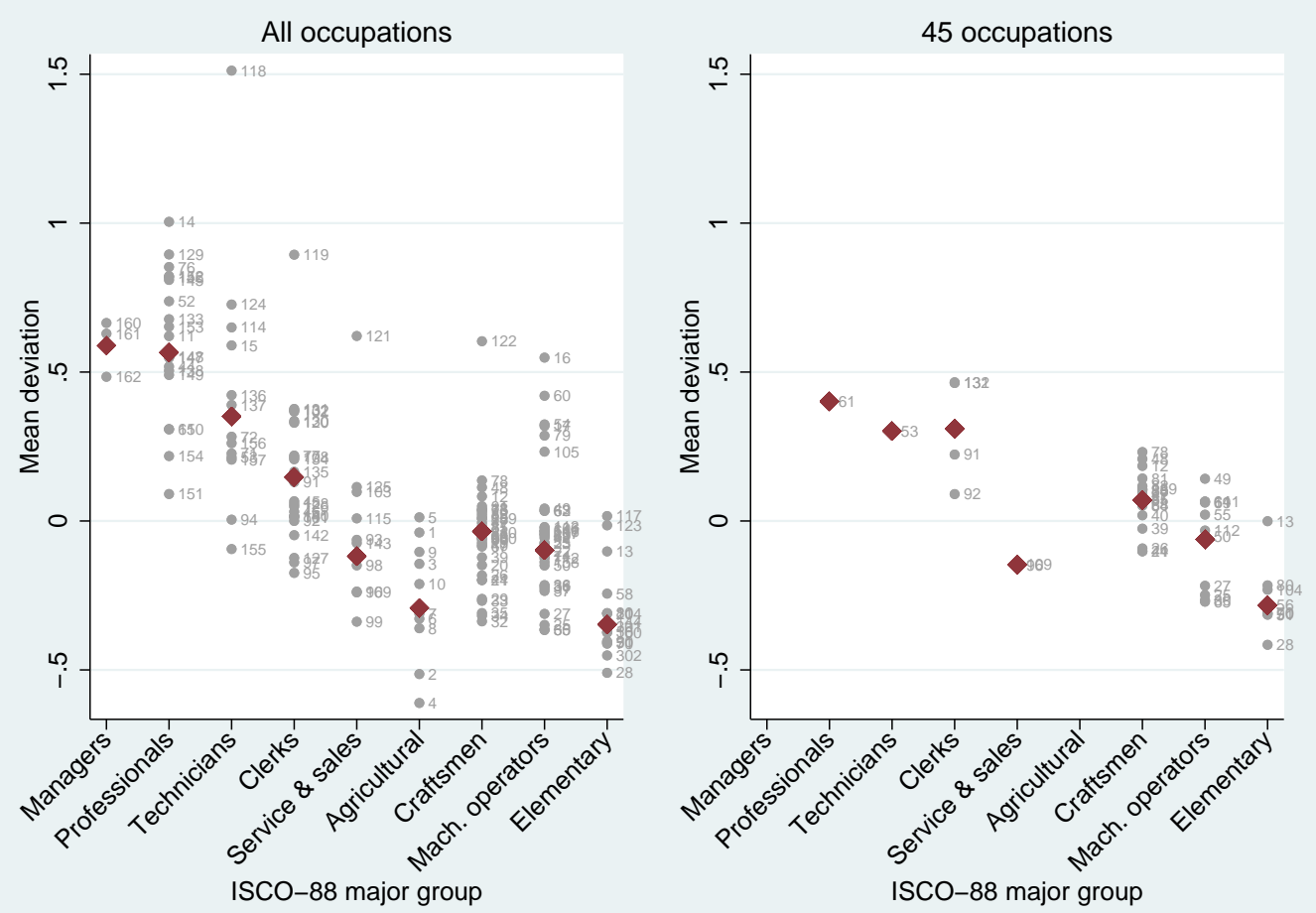

Figure C.1: Dispersion of OWW Wages Within vs. Across Major Groups

Fixed effects are from a regression of log real wages on country, year and occupation or major group dummies. The occupation fixed effects are shown in light grey, labelled with the corresponding occupation code. The fixed effects for the corresponding major group are given by the triangle. Major group dummies account for $60 \%$ of the variation of occupation fixed effects among all occupations, and for $69 \%$ of the variation among the 45 occupations available for the full period. In the full sample, the explained variation increases to $68 \%$ when excluding four highly paid occupations in the airline industry. The labels are occupation codes, cf. Appendix D.

\section{List of Occupations, Industries and Countries from OWW}


45 Occupations Included 1953-2008

\begin{tabular}{|c|c|c|c|c|c|c|}
\hline \multirow[t]{3}{*}{ Skill group* } & \multicolumn{3}{|l|}{ Occupation } & \multirow[t]{3}{*}{ Industry } & \multicolumn{2}{|c|}{ Reports } \\
\hline & Name & Survey & ISCO & & Countries & By year \\
\hline & & code & -88 & & (total) & (avg.) \\
\hline 1 & Underground helper, loader & 13 & 93 & $\mathrm{BA}$ & 82 & 17.4 \\
\hline 1 & Labourer & 28 & 93 & $\mathrm{DA}$ & 145 & 42.5 \\
\hline 1 & Labourer & 51 & 93 & $\mathrm{FB}$ & 161 & 51.8 \\
\hline 1 & Labourer & 56 & 93 & GA & 142 & 39.1 \\
\hline 1 & Labourer & 70 & 93 & JB & 142 & 38.6 \\
\hline 1 & Labourer & 80 & 93 & $\mathrm{KA}$ & 158 & 51.2 \\
\hline 1 & Labourer & 90 & 93 & $\mathrm{LA}$ & 168 & 60.5 \\
\hline 1 & Railway vehicle loader & 104 & 93 & $\mathrm{NA}$ & 124 & 31.6 \\
\hline 2 & Baker (ovenman) & 24 & 74 & $\mathrm{CH}$ & 163 & 55.9 \\
\hline 2 & Thread and yarn spinner & 25 & 82 & $\mathrm{DA}$ & 142 & 40.5 \\
\hline 2 & Loom fixer, tuner & 26 & 74 & $\mathrm{DA}$ & 133 & 35.5 \\
\hline 2 & Cloth weaver (machine) & 27 & 82 & $\mathrm{DA}$ & 143 & 41.4 \\
\hline 2 & Sewing-machine operator & 30 & 82 & $\mathrm{DB}$ & 161 & 50.5 \\
\hline 2 & Furniture upholsterer & 39 & 74 & $\mathrm{~EB}$ & 159 & 50 \\
\hline 2 & Cabinetmaker & 40 & 74 & EB & 160 & 55.9 \\
\hline 2 & Wooden furniture finisher & 41 & 74 & EB & 156 & 47.1 \\
\hline 2 & Hand compositor & 47 & 73 & $\mathrm{FB}$ & 159 & 56.9 \\
\hline 2 & Bookbinder (machine) & 50 & 82 & $\mathrm{FB}$ & 160 & 54.1 \\
\hline 2 & Mixing- and blending- & 55 & 82 & GA & 142 & 34.1 \\
\hline & machine operator & & & & & \\
\hline 2 & Metal melter & 64 & 81 & IA & 121 & 29.7 \\
\hline 2 & Labourer & 65 & 81 & $\mathrm{IA}$ & 130 & 32.1 \\
\hline
\end{tabular}




\begin{tabular}{|c|c|c|c|c|c|c|}
\hline 2 & Bench moulder (metal) & 68 & 72 & $\mathrm{JB}$ & 133 & 36.5 \\
\hline 2 & Machine fitter-assembler & 69 & 82 & JB & 141 & 40.8 \\
\hline 2 & Building painter & 84 & 71 & LA & 168 & 60.1 \\
\hline 2 & Bricklayer (construction) & 85 & 71 & LA & 167 & 59.3 \\
\hline 2 & Cement finisher & 87 & 71 & LA & 156 & 49.7 \\
\hline 2 & Construction carpenter & 88 & 71 & LA & 168 & 62 \\
\hline 2 & Stock records clerk & 92 & 41 & MA & 161 & 47.7 \\
\hline 2 & Salesperson & 96 & 52 & MB & 162 & 52 \\
\hline 2 & Bus conductor & 109 & 51 & NB & 153 & 44.2 \\
\hline 2 & Motor bus driver & 111 & 83 & NB & 163 & 52.5 \\
\hline 2 & Urban motor truck driver & 112 & 83 & $\mathrm{NC}$ & 158 & 46.6 \\
\hline 2 & Automobile mechanic & 159 & 72 & $\mathrm{PF}$ & 159 & 56.1 \\
\hline 3 & Miner & 12 & 71 & BA & 81 & 18.7 \\
\hline 3 & Machine compositor & 48 & 73 & FB & 158 & 54.6 \\
\hline 3 & Printing pressman & 49 & 82 & FB & 160 & 56.8 \\
\hline 3 & Electric power lineman & 78 & 72 & KA & 162 & 53.7 \\
\hline 3 & Building electrician & 81 & 71 & LA & 166 & 57.6 \\
\hline 3 & Plumber & 82 & 71 & LA & 167 & 58.5 \\
\hline 3 & Construction steel erector & 83 & 72 & LA & 162 & 47.7 \\
\hline 3 & Stenographer-typist & 91 & 41 & MA & 155 & 46 \\
\hline 3 & Bank teller & 131 & 42 & $\mathrm{OA}$ & 163 & 49.2 \\
\hline \multirow[t]{2}{*}{3} & Book-keeping & 132 & 41 & $\mathrm{OA}$ & 156 & 44.5 \\
\hline & machine operator & & & & & \\
\hline 4 & Chemistry technician & 53 & 31 & GA & 144 & 32.5 \\
\hline 4 & Occupational health nurse & 61 & 22 & IA & 117 & 22.7 \\
\hline
\end{tabular}

*1=unskilled, $2=$ lower medium skilled, $3=$ upper medium skilled, $4=$ high skilled 


\section{Occupations Included only 1953-1982}

\begin{tabular}{|c|c|c|c|c|c|c|}
\hline \multirow[t]{3}{*}{ Skill group* } & \multicolumn{3}{|l|}{ Occupation } & \multirow[t]{3}{*}{ Industry } & \multicolumn{2}{|c|}{ Reports } \\
\hline & Name & Survey & ISCO & & Countries & By year \\
\hline & & code & -88 & & (total) & (avg.) \\
\hline 1 & Permanent way labourers & 301 & 93 & $\mathrm{NA}$ & 116 & 40.7 \\
\hline \multirow[t]{2}{*}{1} & Labourers (unskilled, & 302 & 91 & $\mathrm{~PB}$ & 134 & 56.3 \\
\hline & public parks and gardens) & & & & & \\
\hline 2 & Pattern makers (wood) & 300 & 71 & $\mathrm{JB}$ & 107 & 38.8 \\
\hline
\end{tabular}

$* 1=$ unskilled, $2=$ lower medium skilled, $3=$ upper medium skilled, $4=$ high skilled

114 Additional Occupations Included 1983-2008

\begin{tabular}{|c|c|c|c|c|c|c|}
\hline \multirow[t]{2}{*}{$\begin{array}{l}\text { Skill } \\
\text { group* }\end{array}$} & \multicolumn{3}{|c|}{ Occupation } & \multirow[t]{2}{*}{ Industry } & \multicolumn{2}{|c|}{ Reports } \\
\hline & Name & $\begin{array}{l}\text { Survey } \\
\text { code }\end{array}$ & $\begin{array}{l}\mathrm{ISCO} \\
-88\end{array}$ & & $\begin{array}{l}\text { Countries } \\
\text { (total) }\end{array}$ & $\begin{array}{l}\text { By year } \\
\text { (avg.) }\end{array}$ \\
\hline 1 & Packer & 21 & 93 & $\mathrm{CA}$ & 105 & 31.5 \\
\hline 1 & Packer & 58 & 93 & GB & 94 & 28.1 \\
\hline 1 & $\begin{array}{l}\text { Room attendant or } \\
\text { chambermaid }\end{array}$ & 100 & 91 & $\mathrm{MC}$ & 127 & 41.6 \\
\hline 1 & Dockworker & 117 & 93 & $\mathrm{NE}$ & 87 & 24.4 \\
\hline 1 & Aircraft loader & 123 & 93 & $\mathrm{NF}$ & 104 & 25.7 \\
\hline 1 & Refuse collector & 144 & 91 & $\mathrm{~PB}$ & 101 & 29.9 \\
\hline
\end{tabular}




\begin{tabular}{|c|c|c|c|c|c|c|}
\hline 2 & Farm supervisor & 1 & 61 & $\mathrm{AA}$ & 93 & 22.9 \\
\hline 2 & Field crop farm worker & 2 & 61 & AA & 105 & 28.2 \\
\hline 2 & Plantation supervisor & 3 & 61 & $\mathrm{AB}$ & 79 & 18 \\
\hline 2 & Plantation worker & 4 & 61 & $\mathrm{AB}$ & 85 & 21.2 \\
\hline 2 & Forest supervisor & 5 & 61 & $\mathrm{AC}$ & 93 & 20.5 \\
\hline 2 & Forestry worker & 6 & 61 & $\mathrm{AC}$ & 96 & 23.8 \\
\hline 2 & Logger & 7 & 61 & $\mathrm{AD}$ & 82 & 20.5 \\
\hline 2 & Tree feller and bucker & 8 & 61 & $\mathrm{AD}$ & 73 & 15.7 \\
\hline 2 & Deep-sea fisherman & 9 & 61 & $\mathrm{AE}$ & 57 & 11.9 \\
\hline \multirow[t]{2}{*}{2} & Inshore (coastal) & 10 & 61 & $\mathrm{AE}$ & 63 & 11.2 \\
\hline & maritime fisherman & & & & & \\
\hline 2 & Quarryman & 19 & 71 & $\mathrm{BC}$ & 82 & 23.8 \\
\hline 2 & Butcher & 20 & 74 & $\mathrm{CA}$ & 115 & 35.4 \\
\hline 2 & Dairy product processor & 22 & 82 & $\mathrm{CB}$ & 107 & 34.7 \\
\hline 2 & Grain miller & 23 & 82 & $\mathrm{CG}$ & 105 & 31.6 \\
\hline 2 & Garment cutter & 29 & 74 & DB & 124 & 37.5 \\
\hline 2 & Tanner & 31 & 82 & $\mathrm{DC}$ & 95 & 26.1 \\
\hline 2 & Leather goods maker & 32 & 74 & $\mathrm{DC}$ & 99 & 26.9 \\
\hline 2 & Clicker cutter (machine) & 33 & 74 & DD & 103 & 28.9 \\
\hline 2 & Laster & 34 & 74 & DD & 96 & 27 \\
\hline 2 & Show sewer (machine) & 35 & 74 & DD & 105 & 30.8 \\
\hline 2 & Sawmill sawyer & 36 & 81 & EA & 107 & 33 \\
\hline 2 & Veneer cutter & 37 & 81 & EA & 91 & 25.6 \\
\hline 2 & Plywood press operator & 38 & 81 & EA & 87 & 24.2 \\
\hline 2 & Wood grinder & 42 & 81 & FA & 75 & 20.9 \\
\hline 2 & Paper-making-machine & 43 & 81 & FA & 83 & 25.2 \\
\hline & operator (wet end) & & & & & \\
\hline
\end{tabular}




\begin{tabular}{|c|c|c|c|c|c|c|}
\hline 2 & Metalworking machine setter & 66 & 72 & $\mathrm{JA}$ & 106 & 32 \\
\hline 2 & Welder & 67 & 72 & $\mathrm{JA}$ & 114 & 38.8 \\
\hline 2 & Electronic equipment assembler & 74 & 82 & $\mathrm{JC}$ & 85 & 25.5 \\
\hline 2 & Reinforced concreter & 86 & 71 & $\mathrm{LA}$ & 122 & 33.9 \\
\hline 2 & Plasterer & 89 & 71 & LA & 116 & 33 \\
\hline 2 & Salesperson & 93 & 52 & MA & 125 & 38.7 \\
\hline 2 & Cash desk cashier & 95 & 42 & $\mathrm{MB}$ & 129 & 40.2 \\
\hline 2 & Hotel receptionist & 97 & 42 & $\mathrm{MC}$ & 126 & 41.3 \\
\hline 2 & Cook & 98 & 51 & $\mathrm{MC}$ & 130 & 45.2 \\
\hline 2 & Waiter & 99 & 51 & $\mathrm{MC}$ & 130 & 44.3 \\
\hline 2 & Ticket seller (cash desk cashier) & 101 & 42 & NA & 80 & 23.7 \\
\hline 2 & Railway steam-engine fireman & 106 & 81 & NA & 51 & 11.8 \\
\hline 2 & Railway signalman & 107 & 83 & NA & 77 & 21 \\
\hline 2 & Automobile mechanic & 110 & 72 & NB & 118 & 37.2 \\
\hline 2 & Long-distance motor truck driver & 113 & 83 & $\mathrm{NC}$ & 104 & 29.7 \\
\hline 2 & Ship's steward (passenger) & 115 & 51 & ND & 68 & 16.1 \\
\hline 2 & Able seaman & 116 & 83 & ND & 85 & 22.6 \\
\hline 2 & Postman & 127 & 41 & $\mathrm{NH}$ & 117 & 34.5 \\
\hline 2 & Stenograper-typist & 140 & 41 & $\mathrm{PA}$ & 105 & 29.8 \\
\hline 2 & $\begin{array}{l}\text { Card- and tape-punching } \\
\text { machine operator }\end{array}$ & 141 & 41 & $\mathrm{PA}$ & 87 & 23.8 \\
\hline 2 & Office clerk & 142 & 41 & $\mathrm{PA}$ & 110 & 33.3 \\
\hline 2 & Fire-fighter & 143 & 51 & $\mathrm{PA}$ & 95 & 27.2 \\
\hline 2 & Ambulance driver & 158 & 83 & $\mathrm{PD}$ & 113 & 34.5 \\
\hline 3 & Supervisor or general foreman & 16 & 81 & BB & 65 & 17.2 \\
\hline 3 & Derricksman & 17 & 81 & $\mathrm{BB}$ & 65 & 15.4 \\
\hline 3 & Miner & 18 & 71 & $\mathrm{BC}$ & 81 & 21.7 \\
\hline
\end{tabular}




\begin{tabular}{|c|c|c|c|c|c|c|}
\hline 3 & Stenographer-typist & 45 & 41 & $\mathrm{FB}$ & 118 & 33 \\
\hline 3 & Office clerk & 46 & 41 & FB & 120 & 36.7 \\
\hline 3 & Supervisor or general foreman & 54 & 82 & GA & 102 & 27.9 \\
\hline 3 & Controlman & 60 & 81 & GC & 69 & 20.2 \\
\hline 3 & Blast furnaceman (ore smelting) & 62 & 81 & IA & 71 & 22.7 \\
\hline 3 & Hot-roller (steel) & 63 & 81 & IA & 67 & 21.7 \\
\hline 3 & Electronics fitter & 73 & 72 & $\mathrm{JC}$ & 81 & 21.8 \\
\hline 3 & Ship plater & 75 & 72 & $\mathrm{JD}$ & 62 & 18.8 \\
\hline 3 & Office clerk & 77 & 41 & KA & 116 & 34.1 \\
\hline 3 & $\begin{array}{l}\text { Power-generating } \\
\text { machinery operator }\end{array}$ & 79 & 81 & KA & 115 & 32.8 \\
\hline 3 & Railway services supervisor & 102 & 41 & $\mathrm{NA}$ & 82 & 20.7 \\
\hline 3 & Railway passenger train guard & 103 & 51 & NA & 74 & 20.3 \\
\hline 3 & Railway engine-driver & 105 & 83 & $\mathrm{NA}$ & 86 & 25 \\
\hline 3 & Road transport services supervisor & 108 & 41 & NB & 105 & 29.7 \\
\hline 3 & Flight operations officer & 119 & 41 & $\mathrm{NF}$ & 100 & 24 \\
\hline 3 & Airline ground receptionist & 120 & 42 & $\mathrm{NF}$ & 105 & 27.2 \\
\hline 3 & Aircraft cabin attendant & 121 & 51 & NF & 104 & 27.7 \\
\hline 3 & Aircraft engine mechanic & 122 & 72 & $\mathrm{NF}$ & 111 & 27.5 \\
\hline 3 & Aircraft accident fire-fighter & 125 & 51 & NG & 86 & 20.5 \\
\hline 3 & Post office counter clerk & 126 & 42 & $\mathrm{NH}$ & 114 & 32.5 \\
\hline 3 & Telephone switchboard operator & 128 & 42 & $\mathrm{NH}$ & 115 & 35 \\
\hline 3 & Stenographer-typist & 130 & 41 & $\mathrm{OA}$ & 116 & 35.5 \\
\hline 3 & Stenographer-typist & 134 & 41 & OB & 103 & 32.1 \\
\hline 3 & $\begin{array}{l}\text { Card- and tape-punching } \\
\text { machine operator }\end{array}$ & 135 & 41 & OB & 92 & 24 \\
\hline 4 & Coalmining engineer & 11 & 21 & BA & 49 & 13.1 \\
\hline
\end{tabular}




\begin{tabular}{|c|c|c|c|c|c|c|}
\hline 4 & Petroleum and natural gas engineer & 14 & 21 & $\mathrm{BB}$ & 60 & 16.4 \\
\hline \multirow[t]{2}{*}{4} & Petroleum and natural gas & 15 & 31 & $\mathrm{BB}$ & 64 & 15.9 \\
\hline & extraction technician & & & & & \\
\hline 4 & Journalist & 44 & 24 & $\mathrm{FB}$ & 113 & 33.5 \\
\hline 4 & Chemical engineer & 52 & 21 & GA & 100 & 27.6 \\
\hline 4 & Electronics draughtsman & 71 & 31 & $\mathrm{JC}$ & 70 & 19.4 \\
\hline 4 & Electronics engineering technician & 72 & 31 & $\mathrm{JC}$ & 86 & 23.8 \\
\hline \multirow[t]{2}{*}{4} & Power distribution and & 76 & 21 & $\mathrm{KA}$ & 118 & 33.4 \\
\hline & transmission engineer & & & & & \\
\hline 4 & Book-keeper & 94 & 34 & MB & 125 & 37 \\
\hline 4 & Ship's chief engineer & 114 & 31 & ND & 79 & 20.7 \\
\hline 4 & Air transport pilot & 118 & 31 & NF & 110 & 27.3 \\
\hline 4 & Air traffic controller & 124 & 31 & $\mathrm{NG}$ & 98 & 27.2 \\
\hline 4 & Accountant & 129 & 24 & $\mathrm{OA}$ & 118 & 37.1 \\
\hline 4 & Computer programmer & 133 & 21 & OB & 97 & 28.2 \\
\hline 4 & Insurance agent & 136 & 34 & OB & 103 & 29 \\
\hline 4 & Clerks of work & 137 & 31 & $\mathrm{OC}$ & 89 & 22.7 \\
\hline 4 & Computer programmer & 138 & 21 & $\mathrm{PA}$ & 97 & 27.7 \\
\hline 4 & Mathematics teacher (third level) & 145 & 23 & $\mathrm{PC}$ & 118 & 33.7 \\
\hline \multirow[t]{2}{*}{4} & Teacher in languages and & 146 & 23 & $\mathrm{PC}$ & 114 & 31.1 \\
\hline & literature (third level) & & & & & \\
\hline \multirow[t]{2}{*}{4} & Teacher in languages and & 147 & 23 & $\mathrm{PC}$ & 120 & 36.2 \\
\hline & literature (second level) & & & & & \\
\hline 4 & Mathematics teacher (second level) & 148 & 23 & $\mathrm{PC}$ & 117 & 34.8 \\
\hline \multirow[t]{2}{*}{4} & Technical education teacher & 149 & 23 & $\mathrm{PC}$ & 114 & 33.8 \\
\hline & (second level) & & & & & \\
\hline 4 & First-level education teacher & 150 & 33 & $\mathrm{PC}$ & 118 & 37.8 \\
\hline
\end{tabular}




\begin{tabular}{|c|c|c|c|c|c|c|}
\hline 4 & Kindergarten-teacher & 151 & 33 & $\mathrm{PC}$ & 113 & 34.6 \\
\hline 4 & General physician & 152 & 22 & $\mathrm{PD}$ & 121 & 39.2 \\
\hline 4 & Dentist (general) & 153 & 22 & $\mathrm{PD}$ & 114 & 33.8 \\
\hline 4 & Professional nurse (general) & 154 & 22 & $\mathrm{PD}$ & 122 & 42.7 \\
\hline 4 & Auxiliary nurse & 155 & 32 & $\mathrm{PD}$ & 118 & 39.3 \\
\hline 4 & Physiotherapist & 156 & 32 & $\mathrm{PD}$ & 109 & 32.9 \\
\hline 4 & Medical X-ray technician & 157 & 31 & $\mathrm{PD}$ & 112 & 35.4 \\
\hline 4 & $\begin{array}{l}\text { Government executive official } \\
\text { - central }\end{array}$ & 160 & 11 & $\mathrm{PA}$ & 95 & 25.3 \\
\hline 4 & $\begin{array}{l}\text { Government executive official } \\
\text { - regional or provincial }\end{array}$ & 161 & 11 & $\mathrm{PA}$ & 77 & 16.5 \\
\hline 4 & $\begin{array}{l}\text { Government executive official } \\
\text { - local authority }\end{array}$ & 162 & 11 & PA & 79 & 18.8 \\
\hline
\end{tabular}

*1=unskilled, $2=$ lower medium skilled, $3=$ upper medium skilled, $4=$ high skilled

\section{Industries of OWW Occupations}

\begin{tabular}{lll}
\hline \hline Industry code & Industry name & ISIC-88 \\
\hline AA & Agricultural production (field crops) & 11 \\
$\mathrm{AB}$ & Plantations & 11 \\
$\mathrm{AC}$ & Forestry & 12 \\
$\mathrm{AD}$ & Logging & 12 \\
$\mathrm{AE}$ & Deep-sea and coastal fishing & 13 \\
$\mathrm{BA}$ & Coalmining & 21 \\
$\mathrm{BB}$ & Crude petroleum and natural gas production & 22 \\
$\mathrm{BC}$ & Other mining and quarrying & 29
\end{tabular}


CA Slaughtering, preparing and preserving meat 31

CB $\quad$ Manufacture of dairy products 31

CG Grain mill products $\quad 31$

CH $\quad$ Manufacture of bakery products 31

DA Spinning, weaving and finishing textiles 32

DB Manufacture of wearing apparel (exc. footwear) 32

DC Manufacture of Leather and Leather Products (exc. footwear) 32

DD Manufacture of footwear $\quad 32$

EA Sawmills, planing and other wood mills 33

EB $\quad$ Manufacture of wooden furniture and fixtures 33

FA Manufacture of pulp, paper and paperboard 34

FB Printing, publishing and allied industries 34

GA Manufacture of industrial chemicals 35

GB Manufacture of other chemical products $\quad 35$

GC Petroleum refineries $\quad 35$

$\begin{array}{lll}\text { IA } & \text { Iron and steel basic industries } & 37\end{array}$

JA Manufacture of metal products (exc. machinery and equipment) 38

JB Manufacture of machinery (exc. electrical) $\quad 38$

JC Manufacture of electronic equipment, machinery and supplies 38

JD Shipbuilding and repairing $\quad 38$

KA Electric light and power $\quad 41$

LA Construction 5

$\begin{array}{lll}\text { MA } & \text { Wholesale trade (grocery) } & 61\end{array}$

MB $\quad$ Retail trade (grocery) 62

MC Restaurants and hotels $\quad 63$

$\begin{array}{lll}\text { NA } & \text { Railway transport } & 71\end{array}$

$\begin{array}{lll}\text { NB } & \text { Passenger transport by road } & 71\end{array}$ 


\begin{tabular}{lll} 
NC & Freight transport by road & 71 \\
ND & Maritime transport & 71 \\
NE & Supporting services to maritime transport & 71 \\
NF & Air transport & 71 \\
NG & Supporting services to air transport & 71 \\
NH & Communication & 72 \\
OA & Banks & 81 \\
OB & Insurance & 82 \\
OC & Engineering and architectural services & 83 \\
PA & Public administration & 91 \\
PB & Sanitary services & 92 \\
PC & Education services & 93 \\
PD & Medical and dental services & 93 \\
PF & Repair of motor vehicles & 95 \\
\hline \hline
\end{tabular}

\section{High Income Countries in OWW}

\begin{tabular}{|c|c|c|c|c|c|c|}
\hline \multirow{3}{*}{$\begin{array}{l}\text { Country code }+ \\
\text { name }\end{array}$} & \multirow{3}{*}{$\begin{array}{l}\text { Reported } \\
\text { occs }\end{array}$} & \multirow{2}{*}{\multicolumn{3}{|c|}{ Years with reports }} & \multirow{2}{*}{\multicolumn{2}{|c|}{ Avg. reports by sample }} \\
\hline & & & & & & \\
\hline & & Total & First & Last & 45 occs & 1983-08 \\
\hline AUS - Australia & 156 & 49 & 1953 & 2006 & 42.1 & 129.7 \\
\hline AUT - Austria & 152 & 50 & 1953 & 2002 & 43.5 & 133.9 \\
\hline BEL - Belgium & 72 & 52 & 1953 & 2004 & 33.6 & 41.9 \\
\hline BHS - Bahamas & 111 & 17 & 1965 & 2007 & 15.4 & 37.8 \\
\hline BRN - Brunei Darussalam & 38 & 14 & 1964 & 2002 & 18.4 & 17.3 \\
\hline CAN - Canada & 131 & 41 & 1953 & 2008 & 24.7 & 86.4 \\
\hline
\end{tabular}




\begin{tabular}{lllllll} 
CHE - Switzerland & 28 & 32 & 1953 & 1984 & 25.3 & 24.5 \\
CYP - Cyprus & 135 & 52 & 1953 & 2006 & 30.1 & 101.9 \\
DEU - Germany & 160 & 56 & 1953 & 2008 & 42.1 & 153.0 \\
DNK - Denmark & 128 & 28 & 1953 & 2007 & 24.1 & 71.1 \\
ESP - Spain & 48 & 23 & 1953 & 1976 & 44.3 & \\
FIN - Finland & 143 & 54 & 1953 & 2007 & 34.4 & 107.2 \\
FRA - France & 20 & 27 & 1955 & 2000 & 6.7 & 1.0 \\
GBR - United Kingdom & 161 & 55 & 1953 & 2008 & 30.4 & 76.4 \\
HKG - Hong Kong SAR, China & 82 & 54 & 1953 & 2008 & 30.7 & 34.7 \\
IRL - Ireland & 91 & 32 & 1953 & 1984 & 36.3 & 79.0 \\
ISL - Iceland & 68 & 54 & 1953 & 2008 & 19.5 & 15.4 \\
ISR - Israel & 54 & 27 & 1953 & 1984 & 29.7 & 21.0 \\
ITA - Italy & 154 & 53 & 1953 & 2008 & 40.4 & 138.7 \\
JPN - Japan & 69 & 46 & 1953 & 2008 & 21.7 & 37.5 \\
KWT - Kuwait & 138 & 8 & 1961 & 2004 & 32.6 & 126.0 \\
LUX - Luxembourg & 88 & 4 & 1977 & 2006 & 18.5 & 54.7 \\
NLD - Netherlands & 107 & 38 & 1953 & 1990 & 36.9 & 76.5 \\
NOR - Norway & 79 & 54 & 1955 & 2008 & 10.3 & 30.0 \\
NZL - New Zealand & 153 & 39 & 1953 & 1991 & 41.5 & 122.2 \\
QAT - Qatar & 35 & 7 & 1972 & 1981 & 30.1 & \\
SGP - Singapore & 152 & 46 & 1953 & 2007 & 32.8 & 87.4 \\
SWE - Sweden & 158 & 43 & 1953 & 1995 & 32.3 & 94.3 \\
TWN - Taiwan, China & 21 & 1953 & 2004 & 40.9 & 77.7 \\
USA - United States & 55 & 1953 & 2007 & 26.3 & 97.8 \\
\hline \hline
\end{tabular}




\section{Middle Income Countries in OWW}

\begin{tabular}{|c|c|c|c|c|c|c|}
\hline \multirow[t]{2}{*}{$\begin{array}{l}\text { Country code }+ \\
\text { name }\end{array}$} & \multirow[t]{2}{*}{$\begin{array}{l}\text { Reported } \\
\text { occs }\end{array}$} & \multicolumn{3}{|c|}{ Years with reports } & \multicolumn{2}{|c|}{ Avg. reports by sample } \\
\hline & & Total & First & Last & 45 occs & $1983-08$ \\
\hline AGO - Angola & 161 & 7 & 1959 & 1999 & 36.1 & 131.0 \\
\hline ARG - Argentina & 150 & 44 & 1953 & 2008 & 24.9 & 54.8 \\
\hline ATG - Antigua and Barbuda & 129 & 19 & 1964 & 1996 & 23.4 & 64.9 \\
\hline AZE - Azerbaijan & 52 & 12 & 1996 & 2008 & 7.2 & 39.1 \\
\hline BGR - Bulgaria & 143 & 2 & 1990 & 2002 & 38.0 & 116.5 \\
\hline BHR - Bahrain & 120 & 24 & 1978 & 2006 & 15.3 & 52.3 \\
\hline BLR - Belarus & 65 & 11 & 1995 & 2007 & 28.4 & 59.9 \\
\hline BLZ - Belize & 112 & 36 & 1953 & 1995 & 26.7 & 90.5 \\
\hline BOL - Bolivia & 149 & 19 & 1953 & 1999 & 36.3 & 102.5 \\
\hline BRA - Brazil & 144 & 16 & 1958 & 2006 & 28.3 & 53.0 \\
\hline BRB - Barbados & 118 & 39 & 1953 & 1995 & 28.3 & 75.0 \\
\hline BWA - Botswana & 84 & 8 & 1975 & 2007 & 17.4 & 37.8 \\
\hline CHL - Chile & 145 & 20 & 1953 & 2007 & 37.7 & 88.8 \\
\hline CIV - CÃŽte d'Ivoire & 161 & 27 & 1956 & 2001 & 35.1 & 96.4 \\
\hline CMR - Cameroon & 123 & 36 & 1956 & 1992 & 30.8 & 56.8 \\
\hline COG - Congo R & 46 & 12 & 1956 & 1979 & 30.5 & \\
\hline COL - Colombia & 143 & 7 & 1958 & 1990 & 27.9 & 73.3 \\
\hline CPV - Cabo Verde & 83 & 5 & 1976 & 1986 & 20.8 & 79.5 \\
\hline CRI - Costa Rica & 162 & 39 & 1958 & 2008 & 39.7 & 112.3 \\
\hline CSK - Czechoslovakia & 123 & 26 & 1958 & 1992 & 32.8 & 90.7 \\
\hline CUB - Cuba & 149 & 16 & 1955 & 2008 & 36.1 & 117.8 \\
\hline CZE - Czech Republic & 136 & 16 & 1993 & 2008 & 36.8 & 109.8 \\
\hline
\end{tabular}




\begin{tabular}{|c|c|c|c|c|c|c|}
\hline DJI - Djibouti & 72 & 4 & 1960 & 1996 & 22.3 & 49.0 \\
\hline DMA - Dominica & 31 & 11 & 1957 & 1984 & 14.3 & 7.0 \\
\hline DOM - Dominican Republic & 115 & 20 & 1954 & 1997 & 25.2 & 71.5 \\
\hline DZA - Algeria & 151 & 31 & 1953 & 2008 & 23.1 & 53.3 \\
\hline ECU - Ecuador & 47 & 5 & 1958 & 1979 & 31.4 & \\
\hline EST - Estonia & 139 & 5 & 1993 & 1997 & 30.4 & 103.4 \\
\hline FJI - Fiji & 139 & 23 & 1953 & 1988 & 25.0 & 102.5 \\
\hline GAB - Gabon & 113 & 23 & 1956 & 1995 & 21.0 & 45.8 \\
\hline GRC - Greece & 48 & 32 & 1953 & 1984 & 41.4 & 41.0 \\
\hline GRD - Grenada & 108 & 22 & 1955 & 1995 & 22.7 & 86.3 \\
\hline GTM - Guatemala & 153 & 21 & 1953 & 1998 & 32.0 & 53.0 \\
\hline HRV - Croatia & 117 & 1 & 1996 & 1996 & 32.0 & 117.0 \\
\hline HUN - Hungary & 149 & 38 & 1957 & 2007 & 28.3 & 124.6 \\
\hline IRN - Iran, Islamic Rep & 71 & 6 & 1959 & 1986 & 24.5 & 43.0 \\
\hline IRQ - Iraq & 41 & 3 & 1959 & 1961 & 38.3 & \\
\hline JAM - Jamaica & 45 & 18 & 1953 & 1979 & 20.4 & \\
\hline JOR - Jordan & 155 & 32 & 1958 & 2006 & 30.3 & 105.9 \\
\hline KAZ - Kazakhstan & 115 & 3 & 2002 & 2004 & 35.0 & 114.0 \\
\hline KGZ - Kyrgyz Republic & 66 & 5 & 1994 & 2002 & 13.2 & 43.0 \\
\hline KNA - Saint Kitts and Nevis & 103 & 16 & 1964 & 2000 & 23.9 & 78.3 \\
\hline KOR - Korea, Rep & 159 & 37 & 1955 & 2006 & 34.6 & 133.4 \\
\hline LBN - Lebanon & 48 & 10 & 1955 & 1968 & 41.0 & \\
\hline LBY - Libya & 34 & 2 & 1975 & 1979 & 21.0 & \\
\hline LCA - Saint Lucia & 111 & 36 & 1955 & 1991 & 22.1 & 71.8 \\
\hline LTU - Lithuania & 139 & 4 & 1995 & 2006 & 27.0 & 90.3 \\
\hline LVA - Latvia & 146 & 10 & 1997 & 2006 & 35.5 & 118.5 \\
\hline MAR - Morocco & 48 & 20 & 1953 & 1979 & 38.8 & \\
\hline
\end{tabular}




\begin{tabular}{|c|c|c|c|c|c|c|}
\hline MDA - Moldova & 122 & 15 & 1994 & 2008 & 28.5 & 88.7 \\
\hline MEX - Mexico & 148 & 43 & 1955 & 2008 & 30.6 & 84.8 \\
\hline MLT - Malta & 35 & 20 & 1953 & 1985 & 23.6 & 7.0 \\
\hline MNG - Mongolia & 22 & 2 & 1994 & 1995 & & 22.0 \\
\hline MUS - Mauritius & 118 & 55 & 1954 & 2008 & 24.9 & 77.3 \\
\hline MYS - Malaysia & 121 & 39 & 1953 & 1995 & 29.9 & 30.8 \\
\hline NAM - Namibia & 36 & 3 & 1996 & 1998 & 5.0 & 17.0 \\
\hline NIC - Nicaragua & 112 & 20 & 1957 & 2002 & 24.7 & 61.9 \\
\hline PAN - Panama & 47 & 9 & 1969 & 1979 & 28.9 & \\
\hline PER - Peru & 152 & 38 & 1963 & 2008 & 31.6 & 72.7 \\
\hline PHL - Philippines & 139 & 35 & 1954 & 2008 & 23.0 & 38.9 \\
\hline PNG - Papua New Guinea & 147 & 7 & 1979 & 1996 & 19.9 & 88.4 \\
\hline POL - Poland & 159 & 7 & 1996 & 2006 & 43.1 & 148.9 \\
\hline PRI - Puerto Rico & 116 & 55 & 1953 & 2008 & 22.5 & 49.0 \\
\hline PRT - Portugal & 145 & 48 & 1953 & 2007 & 24.9 & 72.4 \\
\hline PRY - Paraguay & 47 & 13 & 1953 & 1982 & 37.7 & \\
\hline PSE - West Bank and Gaza & 6 & 2 & 2007 & 2008 & 2.0 & 5.0 \\
\hline ROU - Romania & 162 & 28 & 1973 & 2008 & 43.5 & 152.9 \\
\hline RUS - Russian Federation & 128 & 13 & 1988 & 2007 & 22.3 & 55.5 \\
\hline SEN - Senegal & 91 & 21 & 1956 & 1992 & 32.2 & 49.3 \\
\hline SLV - El Salvador & 149 & 25 & 1959 & 2008 & 36.3 & 123.7 \\
\hline SUR - Suriname & 147 & 29 & 1960 & 1998 & 21.5 & 65.9 \\
\hline SVK - Slovak Republic & 155 & 13 & 1995 & 2007 & 39.7 & 126.8 \\
\hline SVN - Slovenia & 102 & 4 & 1991 & 1997 & 29.3 & 73.8 \\
\hline SWZ - Swaziland & 81 & 11 & 1975 & 1993 & 27.0 & 31.2 \\
\hline SYC - Seychelles & 114 & 19 & 1965 & 1991 & 23.1 & 70.2 \\
\hline SYR - Syrian Arab Republic & 47 & 23 & 1953 & 1995 & 33.0 & 8.0 \\
\hline
\end{tabular}




\begin{tabular}{lllllll} 
THA - Thailand & 141 & 22 & 1954 & 2006 & 31.9 & 109.7 \\
TON - Tonga & 74 & 7 & 1964 & 1985 & 21.7 & 43.5 \\
TTO - Trinidad and Tobago & 138 & 35 & 1953 & 2000 & 26.7 & 98.2 \\
TUN - Tunisia & 128 & 34 & 1954 & 1997 & 33.5 & 59.8 \\
TUR - Turkey & 153 & 10 & 1958 & 2006 & 26.8 & 59.2 \\
UKR - Ukraine & 96 & 5 & 1972 & 1999 & 18.0 & 49.7 \\
URY - Uruguay & 77 & 33 & 1954 & 1995 & 30.7 & 42.5 \\
VCT - St Vincent and Grenadines & 99 & 21 & 1953 & 2003 & 24.9 & 78.5 \\
VEN - Venezuela, RB & 156 & 29 & 1959 & 2001 & 36.7 & 100.8 \\
WSM - Samoa & 109 & 13 & 1968 & 2005 & 25.2 & 71.8 \\
YEM - Yemen, Rep & 148 & 7 & 1968 & 1996 & 28.0 & 146.0 \\
YUG - Yugoslavia & 158 & 10 & 1957 & 1991 & 34.8 & 146.0 \\
ZAF - South Africa & 38 & 13 & 1953 & 1994 & 26.3 & 7.0 \\
ZWE - Zimbabwe & 151 & 18 & 1954 & 2002 & 36.5 & 94.4 \\
\hline \hline
\end{tabular}

\section{Low Income Countries in OWW}

\begin{tabular}{|c|c|c|c|c|c|c|}
\hline \multirow[t]{2}{*}{$\begin{array}{l}\text { Country code }+ \\
\text { name }\end{array}$} & \multirow[t]{2}{*}{$\begin{array}{l}\text { Reported } \\
\text { occs }\end{array}$} & \multicolumn{3}{|c|}{ Years with reports } & \multicolumn{2}{|c|}{ Avg. reports by sample } \\
\hline & & Total & First & Last & 45 occs & 1983-08 \\
\hline AFG - Afghanistan & 22 & 2 & 1958 & 1981 & 12.0 & \\
\hline BDI - Burundi & 97 & 24 & 1963 & 1992 & 32.2 & 64.1 \\
\hline BEN - Benin & 139 & 21 & 1956 & 1991 & 20.7 & 65.9 \\
\hline BFA - Burkina Faso & 121 & 26 & 1956 & 2000 & 24.5 & 61.4 \\
\hline BGD - Bangladesh & 150 & 35 & 1953 & 2007 & 32.7 & 88.2 \\
\hline CAF - Central African Republic & 123 & 25 & 1956 & 1997 & 26.9 & 78.3 \\
\hline
\end{tabular}




$\begin{array}{lllllll}\text { CHN - China } & 131 & 14 & 1990 & 2006 & 26.1 & 69.4 \\ \text { COD - Congo DR } & 150 & 10 & 1953 & 1983 & 36.7 & 146.0 \\ \text { COM - Comoros } & 108 & 15 & 1978 & 1999 & 18.9 & 73.8 \\ \text { EGY - Egypt, Arab Rep } & 141 & 11 & 1987 & 2000 & 25.6 & 85.4 \\ \text { ERI - Eritrea } & 123 & 3 & 1993 & 2000 & 33.3 & 91.7 \\ \text { ETH - Ethiopia } & 70 & 10 & 1955 & 1997 & 26.7 & 23.5 \\ \text { GHA - Ghana } & 152 & 24 & 1954 & 2007 & 34.6 & 97.3 \\ \text { GIN - Guinea } & 46 & 4 & 1956 & 1961 & 28.5 & \\ \text { GMB - Gambia } & 30 & 2 & 1983 & 1984 & 19.0 & 19.0 \\ \text { GNB - Guinea-Bissau } & 37 & 3 & 1977 & 1981 & 23.0 & \\ \text { GNQ - Equatorial Guinea } & 49 & 1 & 1985 & 1985 & 23.0 & 49.0 \\ \text { GUY - Guyana } & 135 & 41 & 1954 & 2007 & 22.5 & 61.5 \\ \text { HND - Honduras } & 151 & 32 & 1955 & 1997 & 34.6 & 109.5 \\ \text { HTI - Haiti } & 61 & 22 & 1953 & 1988 & 24.3 & 35.5 \\ \text { IDN - Indonesia } & 133 & 19 & 1959 & 2006 & 18.1 & 41.8 \\ \text { IND - India } & 103 & 42 & 1953 & 2008 & 23.1 & 63.6 \\ \text { KEN - Kenya } & 101 & 11 & 1957 & 1985 & 27.5 & 77.0 \\ \text { KHM - Cambodia } & 116 & 15 & 1962 & 2001 & 34.9 & 103.8 \\ \text { LAO - Lao PDR } & 13 & 1 & 1955 & 1955 & 13.0 & \\ \text { LBR - Liberia } & 145 & 7 & 1960 & 1986 & 21.8 & 26.5 \\ \text { LKA - Sri Lanka } & 64 & 40 & 1954 & 2000 & 13.2 & 24.1 \\ \text { LSO - Lesotho } & 122 & 5 & 1967 & 1990 & 28.0 & 97.0 \\ \text { MDG - Madagascar } & 15 & 19 & 1956 & 2005 & 33.8 & 103.1 \\ \text { MDV - Maldives } & 2 & 2007 & 2008 & 2.0 & 18.0 \\ \text { MLI - Mali } & 21 & 1956 & 1990 & 33.2 & 96.7 \\ \text { MMR - Myanmar } & 33 & 1970 & 2007 & 32.7 & 131.9 \\ \text { MOZ - Mozambique } & 1987 & 1989 & 32.7 & 115.7\end{array}$




\begin{tabular}{lllllll} 
MRT - Mauritania & 36 & 9 & 1959 & 1971 & 18.3 & \\
MWI - Malawi & 138 & 18 & 1965 & 2002 & 20.2 & 59.3 \\
NER - Niger & 122 & 26 & 1956 & 1988 & 28.2 & 67.8 \\
NGA - Nigeria & 138 & 33 & 1953 & 1997 & 33.5 & 58.7 \\
NPL - Nepal & 117 & 7 & 1975 & 1990 & 32.9 & 68.5 \\
PAK - Pakistan & 159 & 32 & 1953 & 2004 & 40.0 & 108.7 \\
RWA - Rwanda & 131 & 12 & 1962 & 1991 & 33.1 & 123.9 \\
SDN - Sudan & 147 & 23 & 1953 & 1997 & 30.0 & 108.3 \\
SLB - Solomon Islands & 46 & 2 & 1964 & 1986 & 11.5 & 42.0 \\
SLE - Sierra Leone & 114 & 32 & 1954 & 1996 & 26.2 & 98.1 \\
SOM - Somalia & 44 & 5 & 1960 & 1979 & 25.2 & \\
TCD - Chad & 109 & 17 & 1956 & 1999 & 22.2 & 68.0 \\
TGO - Togo & 83 & 24 & 1959 & 1998 & 27.2 & 40.8 \\
TJK - Tajikistan & 114 & 3 & 1993 & 1996 & 14.7 & 44.3 \\
TZA - Tanzania & 41 & 19 & 1953 & 1983 & 26.2 & 10.0 \\
UGA - Uganda & 148 & 4 & 1954 & 1993 & 32.8 & 143.0 \\
VNM - Vietnam & 46 & 20 & 1955 & 1974 & 39.6 & \\
ZMB - Zambia & 34 & 1953 & 2006 & 30.4 & 98.3 \\
\hline \hline
\end{tabular}

